\title{
A corta distancia. Proyectiles esféricos de la Acción de Las Useras, Castellón (17 de Julio de 1839)
}

At short distance. Musket bullets of the Battle of Las Useras, Castellón (July 17, 1839)

\section{CLEMENTE GONZÁLEZ GARCÍA}

Investigador independiente.cgg5550@gmail.com

\section{RESUMEN:}

Este artículo sintetiza uno de los capítulos de la Tesis doctoral del autor: El Ejército del Centro en la provincia de Castellón. Historia militar y arqueología de los campos de batalla, en la Primera Guerra Carlista, (1833-1840). En él se estudian y analizan los proyectiles esféricos documentados en el escenario de la sangrienta batalla de las Useras, ocurrida cuando el general Leopoldo O'Donnell, al frente de sus fuerzas, acudió para socorrer a Lucena del Cid que se encontraba asediada desde hacía semanas por las tropas carlistas. El análisis de la distribución espacial de estos hallazgos permite situar con precisión el suceso histórico y su desarrollo. Muchos proyectiles presentan peculiares deformaciones que se relacionan con la energía que llevaban en el momento de impacto. De este modo se identifican gran cantidad de disparos a corta y muy corta distancia que ayudan a esclarecer las causas de la derrota que sufrió el líder rebelde, Ramón Cabrera, frente a las tropas del Ejército del Centro.

Palabras clave: campos de batalla, proyectiles esféricos, guerras carlistas, detector de metales.

\section{Abstract:}

This article summarizes one of the chapters of the author's doctoral thesis: The Center Army in the province of Castellón. Military history and battlefields archaeology, in the First Carlist War, (1833-1840). This article examines and analyses the spherical projectiles documented in the scene of the bloody Battle of the Useras, which occurred when general Leopoldo O'Donnell, at the head of his forces, came to the aid Lucena del Cid who had been besieged for weeks by the Carlist troops. The spatial distribution analysis of these findings allows the historical event and its development to be precisely located. Many projectiles present peculiar deformations that are related with the energy they were carrying at the moment of impact. In this way, they identify a large number of shots at short and very short distances that help to clarify the causes of the defeat suffered by the rebel leader, Ramon Cabrera, in front of the Center Army troops.

Key words: battlefields, musket bullets, carlist wars, metal detector. 


\section{INTRODUCCIÓN HISTÓRICA}

Lo que hoy conocemos como Primera Guerra Carlista fue una cruel guerra civil que se prolongó durante casi siete años. El conflicto se desencadenó a la muerte de Fernando VII, ocurrida el 29 de septiembre de 1833. Tres años antes el monarca había promulgado la Pragmática Sanción, que convertía en heredera al trono a la infanta Isabel, una niña de apenas tres años. Sin embargo dicha disposición no fue aceptada por el hermano del monarca y sus más próximos seguidores que reclamaron su derecho al trono y decidieron rebelarse en armas. Pero la niña accedió a la corona de forma legítima y, según expresó el general del Ejército del Centro Antonio Van Halen, su proclamación la reconoció casi el total de la nación española, incluso el ejército y cuatrocientos mil voluntarios realistas (Pirala 1868-1869: V, 585). Sin embargo su acceso al trono acabó siendo la excusa para el enfrentamiento entre dos concepciones ideológicas que se oponían en lo político, en lo social y hasta en lo religioso: el liberalismo y el absolutismo.

Sin lugar a dudas fue un periodo desastroso para la nación española, que aún no se había recuperado de los estragos de la Guerra de la Independencia. De nuevo volvieron a repetirse los mismos actos de crueldad y barbarie cometidos veinte años antes contra los invasores franceses y empleando el mismo armamento. Pero esta vez se enfrentaban los españoles de un bando y los del otro. Y todo ello en medio de la más extrema de las miserias económicas que azotó, de manera especial y continuada, a las tropas. Ni siquiera con la Desamortización de bienes eclesiásticos, decretada por el ministro Mendizábal en 1836, se logró obtener suficientes recursos para sufragar la guerra.

Pero el carlismo no fue un movimiento homogéneo y ya en la época se consideraba que había grandes diferencias entre los rebeldes vasco-navarros y los valenciano-aragoneses (Cabello et al. 2006: 107). De hecho, éstos últimos iniciaron la rebelión mostrando sus dos principales características diferenciadoras que persistirían a lo largo de toda la guerra: el robo y el asesinato. El 11 de noviembre de 1833 una partida rebelde asesinó, en Santa Magdalena de Pulpis, al capitán Paniagua para robarle los 52.000 reales que había recaudado en la zona (Sanmartín 1991: 141). Esas diferencias de carácter quedarían patentes tanto en la manera de hacer la guerra como en la de concluirla. Mientras que en el Frente Norte se pactó una paz más que honrosa en Vergara, en el Mediterráneo los rebeldes acabaron de derrota en derrota hasta cruzar la frontera francesa.
En la actualidad, sobre esta contienda se propaga una visión sesgada y, con frecuencia idealizada, a través de multitud de páginas webs que suelen caracterizarse por un aparato gráfico de exaltación monárquica y muy focalizadas en el discurso heroico de las principales batallas. Es necesario tener presente que durante los 40 años de Dictadura franquista el partido único de dicho Régimen fue la Falange Tradicionalista, en el cual militaban los bisnietos carnales y herederos ideológicos de aquellos que se sublevaron en 1833. Esas cuatro décadas de dominio historiográfico, afectaron profundamente al relato histórico, pues una gran cantidad de jefes y oficiales del ejército español que derrotó a los carlistas en el primer tercio del s. XIX, estaban integrados en diversas logias masónicas (García-Municio de Lucas 2018). Y es bien conocido el odio mortal y la persecución sistemática que durante la Dictadura se siguió contra todos aquellos que tuvieran vínculos con dicha sociedad secreta, introducida en el ejército desde el s. XVIII.

De esta manera, durante el franquismo se mitificó a gran escala la figura del principal líder rebelde del carlismo valenciano, el sanguinario Ramón Cabrera ${ }^{1}$, glosando sus éxitos, silenciando sus innúmeras derrotas y convirtiéndolo en una especie de caudillo invencible y popular. Hace apenas catorce años se le erigió una estatua ecuestre en bronce, en el castillo de Morella. Algo verdaderamente insólito si se considera que la Diputación Provincial de Castellón fue el organismo que más esfuerzos y sacrificios realizó para derrotar al audaz y temerario tortosino, causante de la devastación y miseria que asoló las tierras castellonenses.

Y es que en la provincia de Castellón el conflicto tuvo una enorme incidencia debido a que, algunos líderes rebeldes, establecieron sus bases operativas en el sector noroccidental de la misma. Concretamente en la confluencia de los territorios valenciano, aragonés y catalán. Desde dichas bases desarrollaron una intensa actividad bélica y de obtención de recursos que, con el transcurso de la guerra fue in crescendo, dirigida tanto sobre los pueblos, villas y ciudades como contra las fuerzas que el Gobierno destacó para neutralizarlos.

Quizá por todas las razones ya expresadas la historiografía dedicada a la Primera Guerra Carlista en la provincia de Castellón ha centrado su interés, casi de forma monotemática, en la actividad terrestre desarrollada por los rebeldes. Y, de manera preferente, en el sector más montañoso del territorio: Morella y el Maestrazgo, que junto a Cabrera y sus acólitos, parecen haber absorbido el 
interés de los historiadores del s. XX, como si más allá de esto no hubiese apenas nada. Al mismo tiempo, se ignoraba o silenciaba el papel desempeñado por el ejército y los militares españoles. En los últimos años ha surgido una corriente historiográfica, muy focalizada, que se esfuerza en afirmar que el liberalismo de las villas y ciudades castellonenses durante la contienda, sólo fue un mito.

En estos estudios sesgados se acostumbra a enfatizar los casos de insubordinación de las tropas del ejército transmitidos por la bibliografía de referencia, en especial el protagonizado por los Cazadores de Oporto en la capital castellonense. Esta unidad de mercenarios internacionales altamente motivados por razones ideológicas, fue contratada por el Gobierno en Portugal y es indudable que jugó un papel transcendental. Gracias a ellos y a las magníficas cualidades de su jefe, Cayetano Borso di Carminati, la provincia de Castellón no fue completamente dominada por los rebeldes. Sin embargo, esos mismos estudios, ocultan interesadamente o, en el mejor de los casos ignoran, que las principales sublevaciones las protagonizaron las tropas regulares formadas por quintos obligados a servir durante ocho años. Los soldados españoles se amotinaban igual de bien que los belgas y los portugueses, pues las causas que les empujaban a ello, eran las mismas para todos: falta de alimentos, falta de calzado y vestuario, impago de los sueldos, malos tratos por parte de sus jefes, etc. Así, hubo insubordinaciones en Vinaroz, en Villafamés, en Segorbe, en Sagunto, en Peñíscola y hasta en Benicarló donde, por cierto, el jefe de la guarnición fue asesinado por sus propios hombres. En Castellón capital, se dio el caso de que la propia Diputación, bien informada de los ánimos populares, aconsejó al gobernador militar que se marchara a Valencia para no ser linchado por las tropas de la guarnición.

En nuestra investigación doctoral decidimos documentar todos los episodios de combate ocurridos en la provincia de Castellón durante dicho conflicto, añadiendo a los actuales límites provinciales una franja de tolerancia de unos $25 \mathrm{~km}$. El resultado ha permitido identificar casi 400 episodios de enfrentamiento en dicho territorio. Dado que todo ello se gestiona mediante un Sistema de Información Geográfica, es posible reconstruir de manera objetiva y año por año, toda la actividad bélica y la propia evolución de la guerra en la provincia. Además de generar un mapa de calor en el que se identifican los municipios más afectados, podemos también delimitar los principales escenarios bélicos de cara a futuros estudios y a su protección patrimonial como campos de batalla y lugares históricos. Incluso podría llegar a convertirse en algo similar al UK Battelfields Recourse Center difundiéndolo internacionalmente a través de la web ${ }^{2}$.

Uno de estos 400 episodios fue, precisamente, la Acción de las Useras sobre la cual versa el presente artículo. Dicha batalla ocurrió a mediados de julio de 1839 y puso fin al asedio que las tropas rebeldes mantenían desde hacía tres semanas sobre la población de Lucena en donde se habían obligado a encerrarse, por la incapacidad del general Pedro Aznar, una brigada del Ejército del Centro.

\section{PLANIFICACION Y OBJETIVOS}

En agosto de 2012 se realizaron trabajos de prospección arqueológica con detector de metales sobre la parte suroccidental de la sierra de la Cruz. La prospección se desarrolló en torno al monte Gozalvo y varias cotas próximas, todas ellas situadas en el municipio castellonense de Lucena del $\mathrm{Cid}^{3}$. La gran cantidad de materiales y estructuras documentadas permitieron identificar la zona como escenario de una gran actividad bélica.

Al menos dos importantes episodios históricos habían ocurrido en el área de actuación y cada uno de ellos de diferente cronología. El más reciente ocurrió durante los primeros días del mes de junio de 1938, cuando sobre estos montes se libraron intensos combates con abundante empleo de artillería, máquinas automáticas, fusiles y granadas de mano (González Garcia 2015; 2017: 220). Junto a los numerosos materiales vinculados a este suceso de 1938, se identificaron algunos objetos más antiguos, tales como proyectiles esféricos de plomo, una moneda de Carlos IV y diversos botones militares. Entre ellos, uno del Regimiento Provincial de León -ver fig. 7, 2-, permitió relacionar dichos hallazgos con otro importante episodio. La denominada Acción de las Useras, ocurrida el 17 de julio de 1839 durante la Primera Guerra Carlista. En ella se enfrentaron las fuerzas rebeldes del cabecilla catalán Ramón Cabrera, que desde hacía varias semanas asediaban Lucena del Cid y el grueso del Ejército de Centro mandado personalmente por su recién nombrado jefe, el general Leopoldo O’Donnell que acudió desde Zaragoza a marchas forzadas.

La documentación histórica consultada para contextualizar los materiales permitió deducir cómo y dónde pudo haberse desarrollado esa batalla. Además de recurrir a la obras clásicas de referencia, como Cabello et al. (2006), Calbo (1845), Castillo (1860) o Pirala (1868-1869) accedimos a los partes oficiales del combate publicados 
por cada bando (Córdoba 1845: IV, 475 y sig.), a las memorias del general jefe de la Primera División, (Azpiroz 1842) y al Diario de Operaciones del Ejército del Centro correspondiente al mes de julio de 1839 .

Asimismo hay que indicar que existen dos representaciones gráficas relacionadas con este transcendental episodio. Una de ellas, firmada por el capitán de Estado Mayor Miguel Cáceres destinado en el Ejército de Cataluña, presenta una visión de conjunto de gran parte de la provincia de Castellón. En él se indica el recorrido que realizó el ejército liberal desde que salió de Castellón de la Plana hasta llegar a la sierra de la Cruz. Pero su escala, indicada en horas de marcha, supera el 1:50.000. Se trata, por tanto, de una visión global o de conjunto, probablemente realizada por alguien que vivió los hechos desde cierta distancia o que los conoció de oídas. Resulta útil para la comprensión histórica del desarrollo de la acción, pero inadecuada para el trabajo arqueológico. Cuando se ejecutó el trabajo de campo este mapa era el único del que se tenía constancia pues años antes había sido publicado por Escrig (1998: 411).

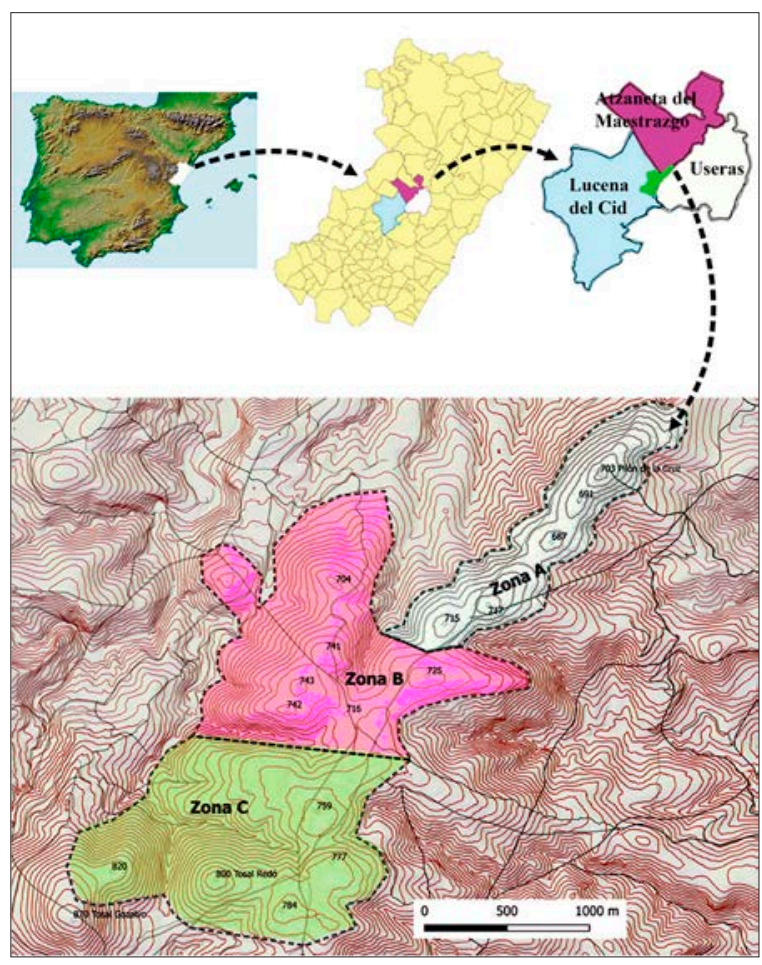

Fig. 1: Mapa de situación. Provincia de Castellón y municipios afectados por los trabajos de prospección. Estructuración en tres zonasdel área a prospectar en 2015. Ilustración del autor a partir de BTN025 del IGN.
Una posterior consulta de los fondos militares permitió descubrir el croquis elaborado por el italiano Manfredo Fanti, capitán de Estado Mayor del Ejército del Centro. De escala mucho más reducida, se trata de un trabajo más técnico centrado en la propia sierra, escenario de la batalla. Está orientado hacia Lucena del Cid (SO). Las cotas se simulan por haces de líneas concéntricas quedando en claro la cima. Incluye abundante información toponímica de las masías implicadas en el escenario de la lucha así como el trazado de los diferentes caminos. El análisis de este dibujo ha permitido reconocer que tan solo representa los movimientos relativos a la fase final de la batalla, la que tiene lugar en torno al monte Gozalvo. En él se omite por completo el enfrentamiento decisivo documentado gracias a nuestra prospección. Este croquis ha sido ya comentado por Faus (2016).

De manera que, tanto las informaciones históricas como los hallazgos realizados en el entorno del monte Gozalvo, apuntaban a que éstos últimos debían estar relacionados con la fase final del combate. Y también que la parte más intensa del mismo se había librado en las crestas de la sierra situadas al $\mathrm{N}$ de dicho monte.

En base a este supuesto se diseñó una nueva prospección, con el objetivo de documentar más elementos que permitieran entender mejor el desarrollo del episodio bélico. Sin descartar, lógicamente, todo aquello que sirviera para complementar los datos relativos a los combates de $1938^{4}$. Este segundo trabajo de campo se realizó durante el mes de junio de $2015^{5}$.

\section{EL MARCO GEOGRÁFICO. TERRENO DE DIFÍ- CIL ACCESO}

La zona a prospectar se extiende sobre la mayor parte de la sierra de la Cruz. Forma un paralelogramo de unos $4 \mathrm{~km}$ en su eje longitudinal por 1,5 km de ancho. Esta sierra sigue una dirección NE-SO y está jalonada por una serie de cimas cuya altitud se sitúa entre los 687 y los 871 m del monte Gozalvo, que es su cota máxima. La cresta de la sierra constituye la línea divisoria de los tres términos municipales que confluyen en ella: Adzaneta del Maestrazgo, Useras y Lucena del Cid. Su importancia estratégica se relaciona con la defensa y control de varias vías de comunicación: por su lado $\mathrm{N}$ la carretera que une Alcora y Adzaneta y por el S de la sierra la que enlaza Alcora con Lucena del Cid. 


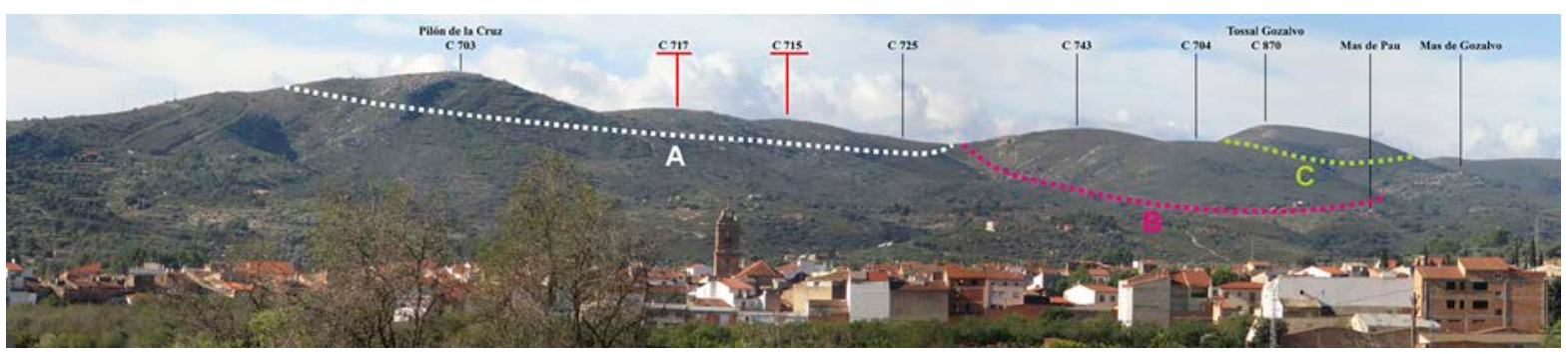

Fig. 2: Panorámica de la Sierra de la Cruz vista desde el cementerio de Adzaneta del Maestrazgo. Fotografía del autor.

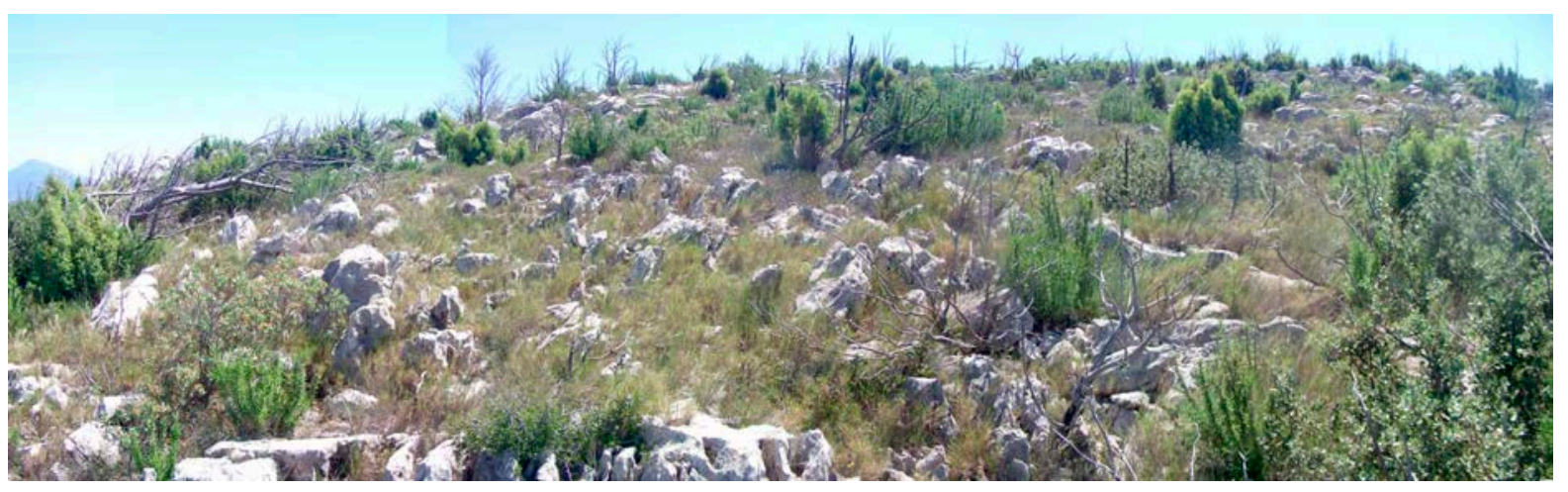

Fig. 3: Zona A. Múltiples afloraciones calizas que dominan la cara O de la cota 715. Fotografía del autor.

La prospección se desarrolló sobre la cresta de la sierra y su ladera noroccidental. Desde la cota 703 -Pilón de la Cruz- en su extremo $\mathrm{N}$, hasta la ladera $\mathrm{N}$ del monte Gozalvo. Con los datos aportados por las fuentes históricas, se decidió ampliar la zona de actuación a las lomas situadas al O de la cresta. Siguiendo la propia trayectoria de la sierra, se dividió el área en tres zonas: A, B y C. La primera englobando las cuatro cotas más septentrionales. La zona $\mathrm{B}$ en la parte central y la zona $\mathrm{C}$ el área situada al S, hasta la ladera del monte Gozalvo, tal como se aprecia en las Figuras 1 y 2.

El terreno es muy desigual y abrupto, con laderas abancaladas por la cara $\mathrm{N}$ de la sierra y pendientes pronunciadas por la cara S. Sólo en la parte central de la zona B hay un amplio espacio relativamente llano. En la mayor parte del área delimitada predomina la vegetación arbustiva y el monte bajo, compuesto por matas de romero y, sobre todo, por grandes núcleos de matas de aliagas. El devastador incendio de 2007 arrasó toda la zona por completo, pero en los últimos años el terreno se ha regenerado de forma espontánea y la vegetación crece con gran fuerza en casi todos los lugares (González 2017: 223-224).
La experiencia adquirida en la campaña de 2012, hacía prever que el tipo de suelo complicaría el trabajo de prospección. Buena parte de él está cubierto por amplias zonas de lapiaz. Estas afloraciones calizas constituyen auténticos campos de minas y dificultan mucho el recorrido a pie. Tal y como muestran las Figuras 3, 4 y 5 en las cimas de la sierra el suelo es muy pedregoso. Algo que, sin duda, fue un factor condicionante para las operaciones militares en la zona. Impidió el empleo de la caballería como arma activa, redujo la movilidad de las tropas de infantería -que en aquella época lo hacían en formaciones cerradas- y afectó, de manera muy importante, a los impactos de los proyectiles disparados durante el combate. Tanto la exuberante vegetación, como las extensas zonas de lapiaz mediterráneo ya citado, impidieron el tránsito e incluso el acceso a determinadas zonas que se consideraban de gran interés.

Por todo ello, y a pesar de planificar la prospección sobre mapa con recorridos de transectos ordenados y regulares, fue imposible realizarlo. La prospección no fue sistemática ni geométricamente regular, sino más bien aleatoria e intensiva en aquellas zonas que, por las características del terreno, resultaron accesibles (González 2017: 227). 


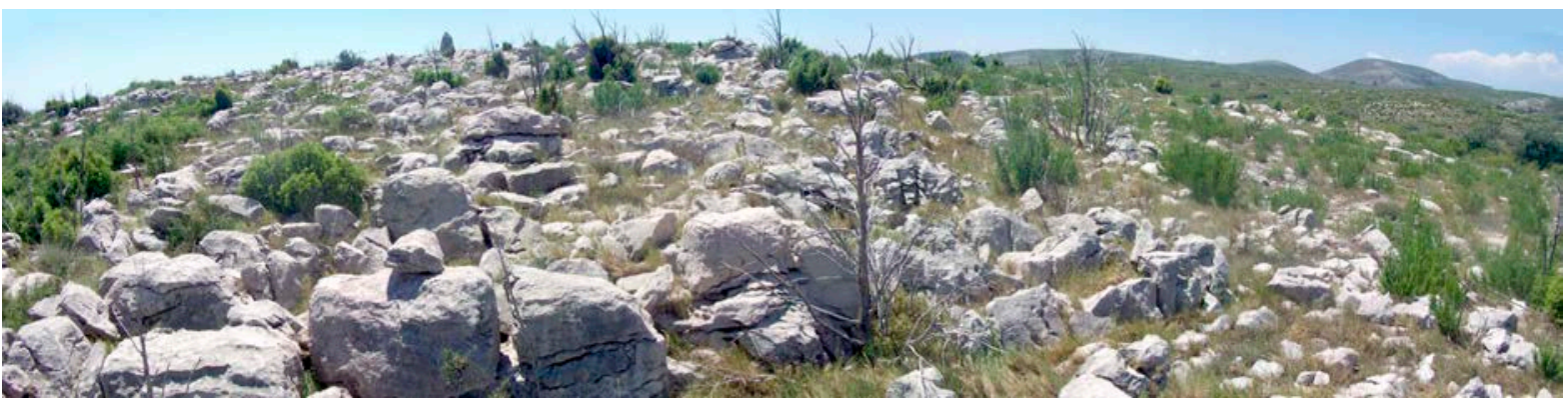

Fig. 4: Zona A. Múltiples afloraciones calizas en la ladera N de la cota 717. Fotografía del autor.

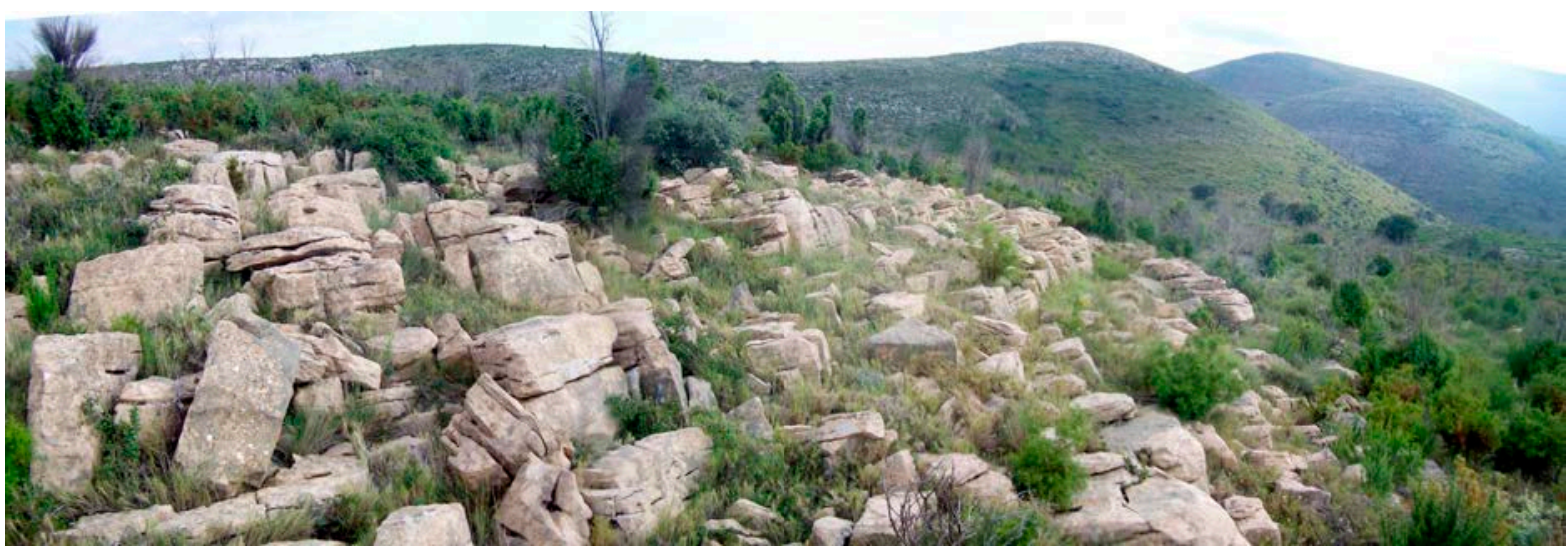

Fig. 5: Zona C. Múltiples afloraciones calizas sobre la cota 759. Al fondo, la cota 800 y, detrás de ella, el monte Gozalvo. Fotografía del autor.

Para poder realizar un trabajo completo y minucioso hubiera sido preciso desbrozar amplios espacios con maquinaria ligera. Por consiguiente queda mucho terreno por prospectar que probablemente aportaría más materiales. Lo cual hace que este trabajo deba considerarse como un estudio preliminar con muchas posibilidades de ser ampliado.

\section{MATERIAL Y MÉTODO}

Desde mediados del s. XV hasta mediados del s. XIX, las armas de fuego portátiles emplearon como munición bolas de plomo de diversos diámetros. A pesar de los innumerables episodios bélicos ocurridos en España en esos 400 años, las investigaciones sobre campos de batalla con este tipo de armamento en nuestro país, se cuentan con los dedos de una mano (Pastor y Adán 2001; Rubio 2009; González 2018; 2020). Y aunque el hallazgo de balas esféricas resulta frecuente en las excavaciones arqueológicas, tanto terrestres (Selma et al. 2015) como subacuáticas (Vivar y Rut 2015; Vivar et al. 2016) por lo general el interés de los arqueólogos se dirige hacia otro tipo de cuestiones y materiales, más que a profundizar en el estudio individualizado de los proyectiles.

Por fortuna, hace ya décadas que en otros países las universidades han creado líneas de investigación en torno a este tipo de materiales, convirtiéndose así en referentes metodológicos muy valiosos para todo aquel que pretenda aventurarse en este ámbito. Desde los diversos artículos del norteamericano Daniel Sivilich y su imprescindible guía para identificar proyectiles esféricos (Sivilich y Miller 2016), hasta el ejemplar estudio del campo de batalla de Lutzen, en Alemania (Shurger 2015), sin olvidar los trabajos relativos a la balística de mosquetes de Willegal (1999), Miller (2010) y, especialmente, el realizado en el museo militar de Graz (Kren et al. 1995) sobre el que se tratará más adelante. En la misma línea, pero más reciente y vinculado con la interpretación arqueológica de los proyectiles de la guerra de independencia norteamericana, hay que destacar el estudio experimental dirigido por 
Douglas Scott (Scott et al. 2016). Pero junto a estos podríamos añadir muchos más ejemplos de prospecciones de campos de batalla donde se empleó este tipo de munición: (Hockensmith et al. 2000; Mandzy et al. 2008; Wrzosek 2012; Homann 2013) sin olvidarnos de aquellos que, además, analizan también la caracterización química de los proyectiles para identificar su origen, como el realizado por Lockman (2006) con materiales del s. XIX o el de las municiones recuperadas en torno al castillo holandés de Gennep vinculadas a una batalla del s. XVII (Huisman et al. 2012). Confiamos que, en las próximas décadas, en alguna facultad española alguien se anime a emprender esta línea de investigación.

Tal y como hemos descrito ya en otro trabajo (González 2018: 223), para realizar el trabajo de campo se emplearon dos herramientas electrónicas fundamentales: la primera un detector de metales con plato de $25 \mathrm{~cm}$, ajustado a todo metal, sin ninguna discriminación. La segunda un receptor GPS comercial enlazado de forma inalámbrica con una PDA. Por lo que se refiere a la metodología, el proceso fue el siguiente: cada objeto detectado se fotografió in situ, se registraron sus coordenadas UTM mediante el GPS de mano. Fue embolsado de manera individual, con una ficha en la que se indicaba su número de inventario, el día y hora del hallazgo y una escueta descripción del mismo.

Tras su limpieza en gabinete y su estudio superficial, muchos de estos proyectiles fueron digitalizados en 3D mediante fotogrametría. Esta técnica ofrece diversos modos de representación que permiten descubrir rasgos y señales que, a simple vista, pasan inadvertidos. Las deformaciones observadas se han puesto en relación con la fórmula de la energía cinética, en la que los factores determinantes son la masa y la velocidad del proyectil, a fin de establecer un posible rango de distancias de disparo capaces de generar dichas deformaciones. Finalmente, toda la información recopilada en el estudio individualizado de cada proyectil se ha volcado en una tabla que ha permitido el análisis espacial de los hallazgos, según sus diversas variables, mediante un SIG.

\section{RESULTADOS}

El material recuperado resultó muy abundante y diverso, ascendiendo a casi 1.500 objetos clasificados, como se aprecia en la Figura 6, en tres grupos cronológicos. El primero relativo a los combates ocurridos en junio de 1938, con predominio de la cartuchería metálica y la metralla artillera. El segundo formado por los materiales claramente relacionados con la batalla del s. XIX. El tercer grupo lo integrarían materiales de cronología más amplia, entre los que se incluyen clavos de herraduras, tachuelas de botas y clavi caligarii, diversas monedas una de ellas un semis de Augusto-, varias puntas de flecha de hierro probablemente romanas y otros objetos de imprecisa clasificación.

\section{OBJETOS RELACIONADOS CON LA BATALLA: BOTONES Y METRALLA}

Entre los restos metálicos vinculados con el episodio bélico de la Primera Guerra Carlista se documentaron botones, alguna moneda y fragmentos de granadas esféricas de hierro empleadas por la artillería. Los botones (fig.7) constituyen un elemento de gran importancia. Aportan información histórica y pueden incluso facilitar una cronología absoluta. Los estudios sobre catalogación de botones militares (Guirao 1999; Guirao et al. 2013) permiten una rápida identificación de las piezas y su atribución cronológica.

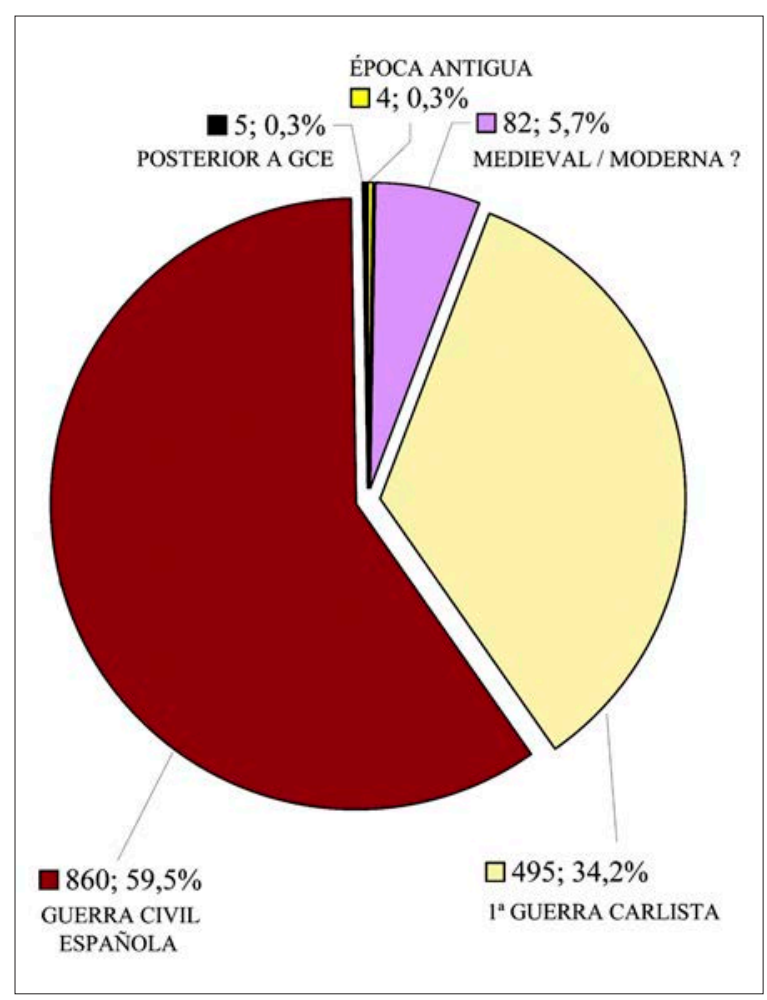

Fig. 6: Gráfico resumen de los materiales encontrados, por época. Ilustración del autor. 


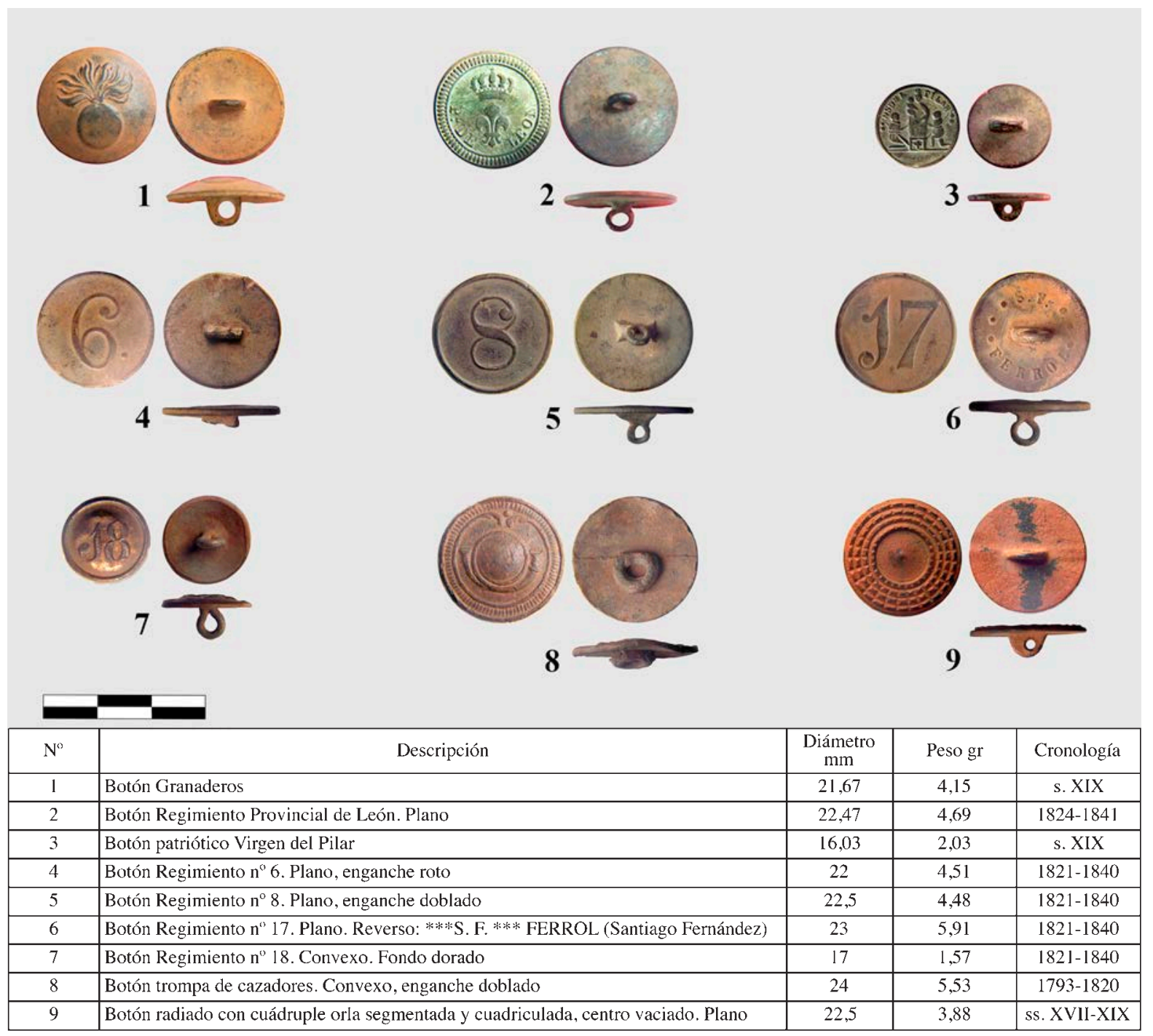

Fig. 7: Botones documentados en la Sierra de la Cruz y tabla descriptiva de los mismos. Elaboración propia.

Los fragmentos de artillería de avancarga, como el que se muestra en la Figura 8, se documentaron en la zona C. Todos ellos son de hierro y pertenecen a proyectiles esféricos huecos, es decir granadas, cuyo diámetro exterior se aproximaría a los $120 \mathrm{~mm}$. Probablemente correspondan con el calibre de 5 pulgadas $^{6}$. El grosor de las paredes varía de 15,20 a 16,90 $\mathrm{mm}$. La mayoría de ellos hay que atribuirlos a las tropas de O'Donnell. Tan solo uno se diferencia claramente del resto. Su diámetro exterior es algo superior a los otros y también su composición interna. Se trata de un fragmento de hierro de color gris claro, que quizá perteneció a una bala maciza. Presenta abundantes y grandes poros en su estructura que parecen indicar una fundición artesanal y que lo diferencia claramente de los otros restos, de mejor calidad, textura compacta y $\sin$ poros.

\section{PROYECTILES ESFÉRICOS DE AVANCARGA}

Sobre la sierra de la Cruz se documentaron una gran cantidad de proyectiles de plomo vinculados con la batalla de 1839 (fig. 9). En total ascienden a 495 piezas, lo que constituye un conjunto muy numeroso. Máxime si se compara con los hallazgos obtenidos al estudiar otros 
campos de batalla de nuestro país, en los que se empleó también armamento de avancarga, como por ejemplo los de Somosierra (Pastor y Adán 2001) o Talamanca (Rubio 2009). Sin embargo, es preciso reconocer que se trata de una cantidad ínfima si se compara con los disparos que, seguramente, se realizaron. A partir de las unidades que se enfrentaron en este sector, estimamos que pudieron dispararse en torno a 320.000 proyectiles de fusil. En tal caso, los escasos 500 hallazgos no llegarían ni al 0,2\% de la cantidad disparada ${ }^{7}$.

Uno de los problemas que surgen al estudiar estos proyectiles es el de su representación gráfica. Al tratarse de esferas, que en muchos casos sufren fuertes deformaciones, la fotografía convencional en dos dimensiones es incapaz de transmitir todo lo que se aprecia sobre el objeto real. Por esta razón se recurrió al empleo de la fotogrametría de rango corto, con resultados altamente satisfactorios. Algunas de las ilustraciones que acompañan este artículo se han realizado a partir de los modelos fotogramétricos tal como se puede apreciar en la Figura 12.

\section{CLASIFICACIÓN DE LOS PROYECTILES}

La gran cantidad de proyectiles recuperados (fig.10), ha permitido establecer dos sistemas clasificatorios. El primero de ellos atendiendo a su grado de deformación superficial. Está enfocado a obtener información sobre la distancia a la que el proyectil fue disparado. El segundo atiende a las diferencias del metal empleado para fabricarlos y a las marcas causadas durante el proceso de elaboración. Podría servir para asignar los proyectiles a un determinado bando.

\section{POR SU DEFORMACIÓN Y TIPO DE IMPACTO}

Debido a la plasticidad característica del plomo, cuando la bala impacta sobre superficies duras tiende a deformarse y perder su esfericidad primitiva. Para una misma superficie, esa deformación será más acusada cuanta más energía cinética lleve el proyectil en el momento del impacto. Dicha energía cinética está directamente relacionada con la masa del proyectil pero, sobre todo, con la velocidad del mismo. Así se desprende de la fórmula $E \operatorname{cin}=1 / 2 * M * V^{2}$, donde $M$ representa la masa del proyectil en $\mathrm{kg}$ y $V$ su velocidad en $\mathrm{m} / \mathrm{s}$. Como puede apreciarse, duplicando la masa del proyectil se duplica la energía cinética, mientras que al duplicar la velocidad, el resultado es cuadruplicar la energía cinética (Gallusser et al. 2002: 77-78).

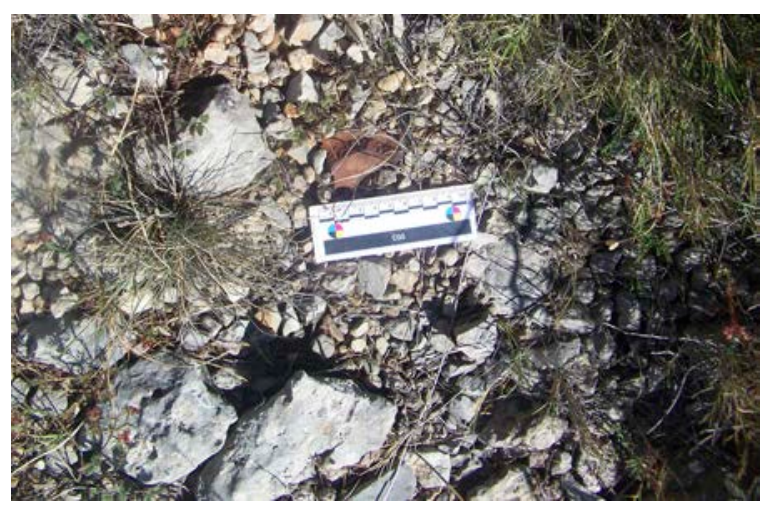

Fig. 8: Hallazgo de un fragmento de metralla esférica probablemente disparado por los obuses del general O'Donnell contra la cota 800 . Fotografía del autor.

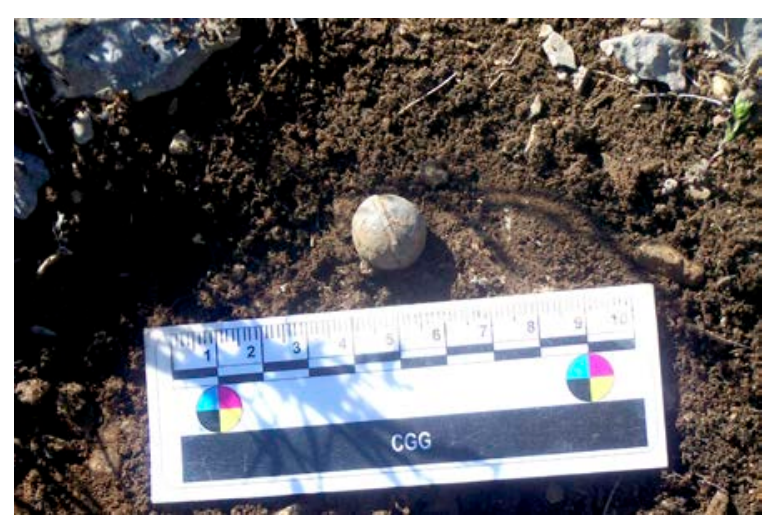

Fig. 9: Hallazgo de un proyectil esférico que presenta acusada línea de molde. Fotografía del autor.

Dado que la forma esférica es la menos aerodinámica para un proyectil, éste tiende a perder velocidad desde el mismo momento que sale por la boca del arma. Por tanto, a mayor distancia entre el punto de disparo y el de impacto, menor velocidad tendrá la bala al impactar y también será menor la deformación que sufrirá y viceversa. Cuando se dispara a muy corta distancia de un objetivo sólido, el proyectil impacta con tanta velocidad y energía que se deforma mucho y de manera muy característica según sea la superficie y el ángulo de impacto. En algunos casos, el plomo llega a conservar la huella de la superficie contra la que choca, identificándose diversos tipos de improntas.

Los diferentes estudios científicos realizados, tanto en el s. XIX como en nuestros días, han demostrado que la mayoría de las armas de avancarga lanzaban los proyectiles a más de $400 \mathrm{~m} / \mathrm{s}$, velocidad que descendía rápidamente 


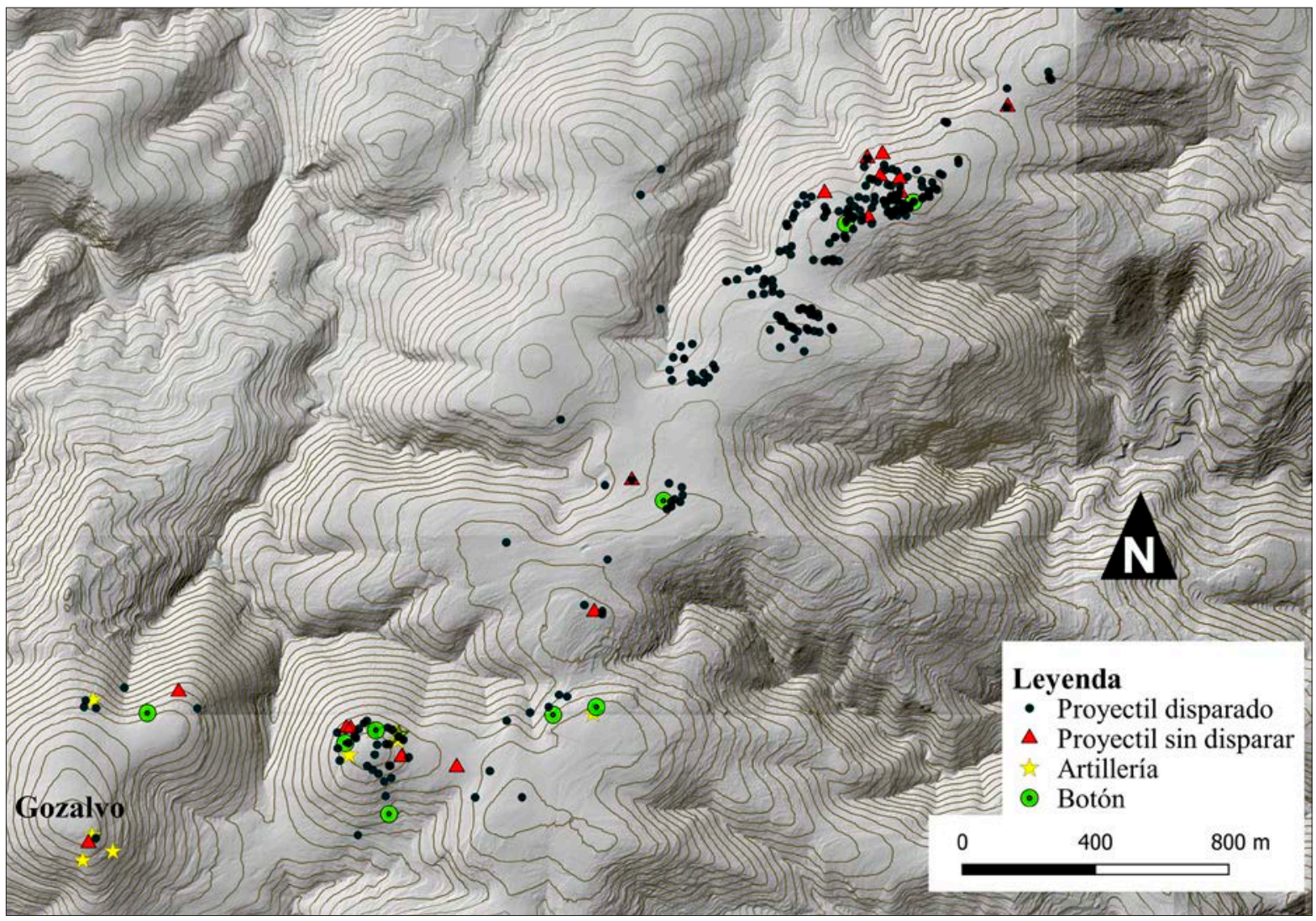

Fig. 10: Mapa de los hallazgos relativos a la Acción de Las Useras. Se aprecian zonas con mayor concentración de proyectiles esféricos, lo cual podría ser indicador de dónde fue más intensa la batalla. Ilustración del autor sobre BTN25 del IGN.

debido, sobre todo, a la resistencia ofrecida por el aire. Semejante velocidad es similar a la que lleva una bala de $9 \mathrm{~mm}$ disparada por una pistola actual, con la diferencia de que el proyectil moderno mantiene durante mucho tiempo esa velocidad y por tanto su energía cinética y su capacidad letal ${ }^{8}$.

Uno de los primeros trabajos científicos dedicados a esta cuestión se realizó en 1988 en colaboración con el museo militar de Graz, en Austria (Krenn et al. 1995). Sus resultados han sido considerados la mejor base de datos cuantitativa sobre las propiedades de las armas de avancarga, tales como velocidad inicial, trayectoria, precisión del arma, niveles de energía y capacidad de penetración de los proyectiles. El test de Graz confirmó que la velocidad inicial en todas las armas usadas en la prueba fue superior a la del sonido y sorprendentemente alta, con una media de $454 \mathrm{~m} / \mathrm{s}$. Pero también que esta elevada velocidad inicial se reducía rápidamente debido al rozamiento aerodinámico. Los proyectiles perdían la mayor parte de su velocidad entre los primeros 30 a $50 \mathrm{~m}$ de vuelo. Así, las balas esféricas usadas en las pruebas fueron deceleradas en un rango de $2,5 \mathrm{~m} / \mathrm{s}$ por cada metro de distancia recorrido durante los primeros $24 \mathrm{~m}$ de su trayectoria. Quedó probado que los proyectiles esféricos pierden velocidad tres veces más rápido que las balas modernas. Y a pesar de tener mayor masa que éstas, tales pérdidas de velocidad suponen una menor energía de impacto.

Recientemente, Douglas Scott -el pionero de la arqueología de los campos de batalla por su trabajo de 1983 en Little Big Horn-, ha desarrollado un proyecto similar al test de Graz. Pero no se ha limitado a la obtención de datos técnicos cuantitativos, sino que el enfoque experimental se ha orientado a la obtención de información útil para la interpretación arqueológica de los proyectiles 9 . A partir de los resultados de su experimento ha establecido un Índice de Deformación del Proyectil de Plomo basado en un conjunto mixto -cualitativo y cuantitativo- de 
observaciones sobre el proyectil disparado. Dicho índice permite establecer una escala clasificatoria midiendo en cada proyectil su diámetro máximo, su espesor o cantidad de aplanamiento y el diámetro mínimo. Dicha escala otorga el valor 1 para proyectiles cuya velocidad probable sea inferior a $243 \mathrm{~m} / \mathrm{s}$ y en los que las medidas del diámetro son consistentes en los tres puntos del proyectil. El valor 2 corresponde a una velocidad probable de entre 243 y 335 m/s, según los impactos visibles, leves o moderados y cuando el aplanamiento sea menor de la mitad de la bola. El valor 3 se asigna a una velocidad superior a $\operatorname{los} 335 \mathrm{~m} / \mathrm{s}$, con abundantes impactos, deformaciones y aplanamientos severos. Para casos dudosos los autores proponen utilizar el 0,5 como medida entre escalas (Scott et al. 2016: 59-60).

Todo lo cual guarda una estrecha vinculación con el trabajo que aquí presentamos, desarrollado a partir de materiales arqueológicos. Nuestra hipótesis de partida se fundamenta en que la mayoría de las deformaciones que presentan los proyectiles recuperados en la sierra de la Cruz, estarían directamente relacionadas con la energía cinética que conservaran en el momento del impacto. Y que dicha energía está estrechamente vinculada a la distancia entre el punto de disparo y el de impacto. Por tanto, el grado y tipo de deformación que presentan los proyectiles esféricos de plomo, podría ser un indicador de la distancia a la que fueron disparados. Gracias al empleo de un SIG y cartografía referenciada, podríamos situar espacialmente a las fuerzas combatientes y explicar la dinámica de la lucha.

A diferencia de nuestros colegas norteamericanos, hemos optado por establecer una clasificación de 10 tipos distintos, partiendo del estado original del proyectil hasta su mayor deterioro. De este grupo se han excluido los proyectiles de bronce que se estudiarán más adelante.

\section{TIPO 1. PROYECTIL ESFÉRICO SIN DISPARAR}

Engloba aquellos proyectiles de plomo que conservan completa su forma esférica y en los que no se aprecian marcas ni de impacto ni de disparo. El conjunto asciende a 35 piezas. En estos proyectiles es donde mejor se puede descubrir la técnica empleada para su fabricación, así como la calidad final de los mismos. Al no haber sido disparados ni sufrir deformaciones, también son los que permiten medir el diámetro real con el mayor grado de precisión.

Pero, ¿a qué obedece que estos proyectiles se encuentren en el campo sin haber sido disparados? Hay varias posibles respuestas. Una casual, otras intencionadas. En el primer caso se trataría de cartuchos perdidos

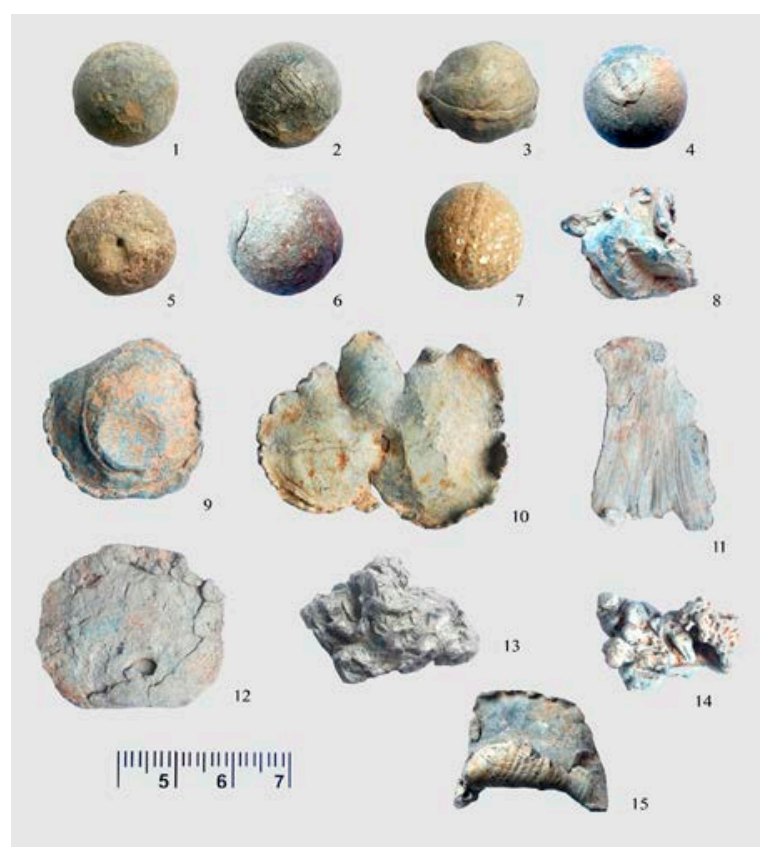

Fig. 11: Muestra representativa de la diversidad de proyectiles documentados. Ilustración del autor.

involuntariamente por los soldados durante sus movimientos por el campo de batalla. De la misma manera que en los escenarios de la Guerra Civil del s. XX son muy abundantes los cartuchos sin disparar, que se caían de las cartucheras cuando los soldados corrían, se arrojaban al suelo o simplemente se les resbalaban de las manos por efecto del miedo o nerviosismo durante el combate.

Mientras que los rebeldes carlistas empleaban cananas para transportar la munición, el soldado gubernamental llevaba una gran cartuchera de cuero. Terciada sobre el cuerpo mediante una correa, la cartuchera quedaba situada en la parte posterior, aproximadamente sobre la nalga derecha. Se conocen perfectamente sus dimensiones pues alguna de ellas ha sido recuperada en recientes excavaciones arqueológicas (Arévalo 2010: 195-205). Cuando el soldado tenía que cargar el fusil, movía hacia atrás su mano derecha, abría la cartuchera y extraía un cartucho. Originariamente los cartuchos se agrupaban en paquetes de 10, atados con bramante y en la cartuchera entraban entre cinco y seis paquetes según el diámetro de la bala. De modo que, para agilizar el tiro durante el combate, es lógico suponer que previamente el soldado desliara algún paquete. Y eso facilitaba las pérdidas. Esta hipótesis aparece confirmada incluso en los manuales de 
la época, donde se previene al soldado que, a la hora de cargar el arma, cuide ...de no derramar la pólvora al cebar y de no dejar caer cartuchos al sacarlos de la cartuchera (Reglamento 1837: 99-100).

Por otra parte, cada vez que el soldado se sentaba o se tumbaba en el suelo, la cartuchera perdía su posición vertical facilitando así la salida involuntaria de los cartuchos. El uso continuado de las mismas y las dificultades de reposición del material que sufrieron estos soldados según indican las fuentes documentales, hace pensar que el estado de muchas cartucheras, a las que por Reglamento se les asignaba una vida útil de 12 años (Clonard 1851: VI, 481), no debía ser muy satisfactorio. Roturas, perforaciones, cierre defectuoso, etc., facilitaban el goteo continuo de pérdidas de munición. Por otra parte, al soldado gubernamental, tras cada acción de combate se le reponía su dotación de cartuchos, por lo que es probable que no tuviera mucho interés en recoger los que veía pisoteados $\mathrm{y}$ rotos por el suelo.

A tenor de todo lo anterior, cabe suponer que una gran parte de los proyectiles no disparados que han sido documentados podrían pertenecer al bando liberal y que probablemente pudieron perderse en aquellas zonas donde los soldados llegaron a sentarse, tumbarse o caerse.

Pero además de la hipótesis de la pérdida involuntaria -quizá la causa más probable y extendida para estos proyectiles-, existe otra explicación. Tal vez no tan intensa ni frecuente, pero que al menos conviene tener presente. No tiene nada que ver con cuestiones físicas ni materiales, sino ideológicas. Por un lado está la voluntad de no querer matar, vinculada a creencias religiosas arraigadas. Por otra parte pueden ser casos de colaboracionismo de algunos soldados liberales con el enemigo y viceversa. El oficial de Ingenieros alemán Wilhelm von Rahden, perteneciente al Estado Mayor del caudillo rebelde Cabrera, relata que durante el sitio de Cantavieja un muchacho desertó del Ejército del Centro y se pasó a los carlistas. Interrogado sobre su comportamiento durante la batalla afirmó que no había disparado ni un solo tiro contra sus paisanos aragoneses, asegurando que todas sus balas estaban limpias en el campo de batalla. Afirmaba que al igual que él actuaron otros muchos de su compañía que aún no se habían atrevido a desertar. Cuenta von Rahden que durante los días siguientes se recogieron en el campo de batalla varios cientos de balas de fusil ...en parte todavía envueltas en sus cilindros de papel y sin rastro alguno de pólvora.
Yo estuve presente cuando estas balas fueron entregadas a Cabrera. Profundamente conmovido, faltó poco para que el general hubiese abrazado al muchacho. Lo nombró sargento de un batallón del Turia (Von Rahden et al. 2013: 340).

Es decir, había soldados que al recibir la orden de disparar abrían fuego como el resto de la línea. Pero en realidad lo que disparaban era salvas. El proyectil no lo introducían en el fusil, sino que de manera disimulada lo arrojaban al suelo. Y esa es otra explicación a tener en cuenta para este tipo de hallazgos.

De todo lo expuesto anteriormente se deduce que estos proyectiles aportan información sobre el tipo de armamento empleado y su calibre; sobre la situación de los soldados y, de manera especial, sobre sus zonas de descanso o vivac. Sin embargo no permiten deducir alcances, trayectorias, distancias ni emplazamiento de las tropas contrarias.

\section{TIPO 2. PROYECTIL ESFÉRICO IMPACTADO}

El siguiente tipo de proyectil que se ha diferenciado es muy similar al anterior. De hecho conserva buena parte de su forma esférica hasta el punto que en algunos casos puede medirse su diámetro sin excesivo error.

Se trata de un conjunto de 74 piezas caracterizado porque todas ellas muestran en su superficie leves señales de impacto o la característica marca del viento balístico, (fig. 12, A). Y esta es otra de las razones que permiten afirmar que algunos proyectiles que componen este grupo sí fueron disparados. No obstante, los escasos daños que presentan invitan a plantear varias posibilidades durante su empleo.

a) Buena parte de la pólvora del cartucho se derramó fuera del fusil y fueron disparados con una carga de pólvora muy inferior a la necesaria. Caso posible pero poco probable y mucho menos hasta el punto de generalizarse, además entre tropas tan veteranas como las que participaron en esta batalla.

b) Fueron disparados en armas de calibre mayor al del diámetro del proyectil y, por tanto, gran parte de la presión de los gases se escapó por la boca del arma sin proyectar la bala con la energía necesaria. En este caso tendrían que ser proyectiles de diámetro inferior al del fusil inglés. Esta opción, como luego se verá, resulta muy posible.

c) Impactaron en un terreno especialmente blando o fueron frenados por hojas, hierbas, etc. Poco probable a tenor del tipo de suelo. 
d) Fueron disparados a tal distancia que cuando llegaron al punto de impacto habían perdido la mayor parte de su energía cinética. En tal caso, podrían servir como indicadores de disparo lejano. Pero, ¿a qué distancia en concreto? Eso ya es más complicado de establecer con exactitud. Sobre todo teniendo en cuenta que el alcance máximo -que no eficaz- de los fusiles estaba en torno a $900 \mathrm{~m}$. No obstante, si atendemos a la instrucción que, según el Reglamento de Infantería (1837: I, 207-208), recibieron estos soldados, no hay duda de que se les enseñó a disparar a largas distancias: Siendo de la mayor importancia acostumbrar a los Soldados a dirigir bien sus tiros, se les ejercitará en tirar al blanco, primero a la distancia de 50 toesas $(97,45 \mathrm{~m})$, después a la de 150 (292,4 m) y últimamente a la de 200 (389,8 m)...

En la misma época el comandante Ramón de Salas indicaba las siguientes reglas de puntería: ... a 300 toesas $(584,7 \mathrm{~m})$ se apuntará a lo alto de las banderas o banderolas de guías. A 200 toesas $(389,8 \mathrm{~m})$, ídem a las bayonetas estando el enemigo armas al hombro. A 150 toesas (292,4 m), idem a las cabezas del enemigo. A 100 toesas (194,9 m), ídem a la cintura del enemigo. A 60 toesas (116,9 m), ídem a las rodillas de los enemigos (De Salas 1833: 395).

Por todo lo cual, no puede descartarse la posibilidad de que los disparos que se realizaron a larga distancia lo fueran a unos $400 \mathrm{~m}$.

\section{TIPO 3. PROYECTIL SEMI-REDONDO}

El Tipo 3 se trata del grupo más numeroso de hallazgos con un total de 112 piezas. Se han agrupado en él aquellos proyectiles cuyo perfil todavía recuerda a la esfera, pero cuyas deformaciones por impactos y rebotes son tales que, en la gran mayoría de los casos, ya no es posible medir su diámetro de forma fiable (fig. 12, B). Al no poder medir su diámetro se ha optado por medir su altura o espesor, -lo que Scott en su experimento denomina aplanamiento- lo cual se aplicará también a las siguientes tipologías. Los del Tipo 3 se sitúan en una banda de espesor de entre 8 y 17,6 mm. En muchos de ellos se aprecian claras pérdidas de material.

\section{TIPO 4. PROYECTIL DEFORMADO}

Este conjunto de 66 piezas se caracteriza, más que por tener alguna cuestión en común, por no tenerla. No son esféricos y han sufrido múltiples impactos y rebotes. Ello ha dado lugar a que sus formas sean muy variadas y caprichosas (fig. 12, D y E). Sin embargo no es posible

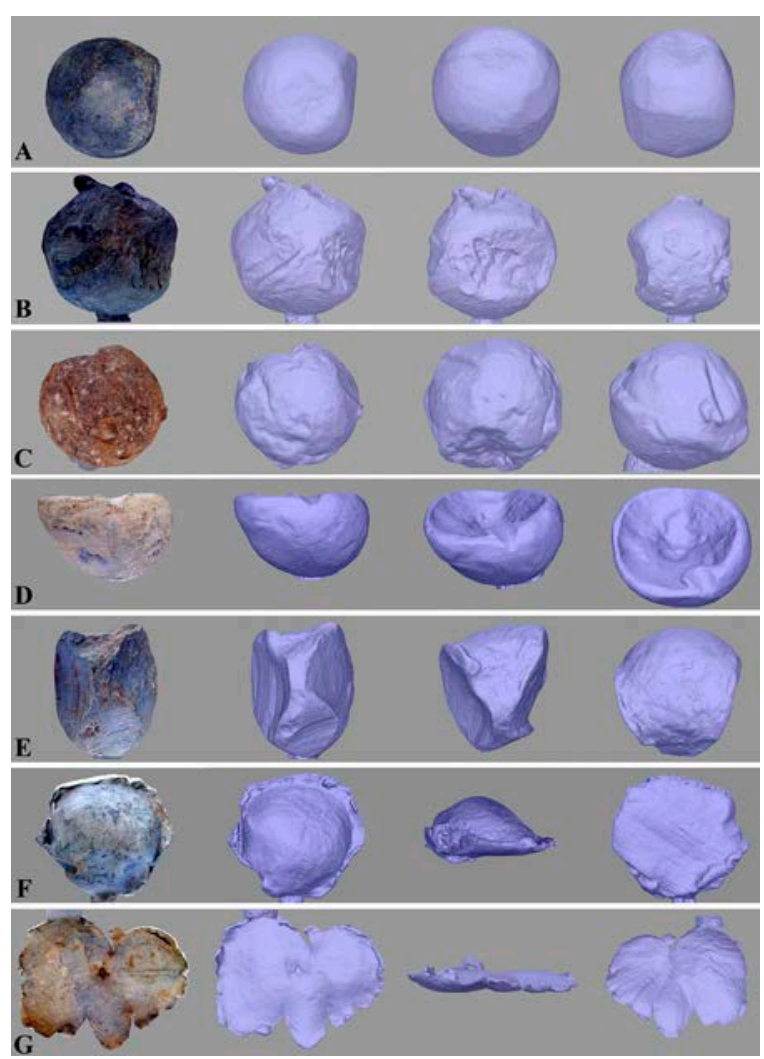

Fig. 12: Fotogrametrías de varios proyectiles con diversos tipos de deformación. A la izquierda se presenta el modelo en vista con textura, en el resto se ofrece la vista en modo sólido. Ilustración del autor.

incluirlos en los posteriores grupos T5 y T6. Por su aspecto y nivel de deformación este tipo se ha considerado, al igual que el grupo anterior, disparados a media distancia. La gran mayoría están incompletos y han sufrido pérdidas de sustancia.

\section{TIPO 5. PROYECTIL DEFORMADO HUEVO FRITO}

Este grupo, integrado por 58 piezas, presenta una característica singular. En su mayoría han sufrido un único impacto y probablemente en un ángulo de $90^{\circ}$. Pero además dicho impacto se ha producido a una distancia claramente inferior a los anteriores. Ello ha provocado que el proyectil se deforme de una manera muy peculiar. Una forma muy gráfica de definirlo es por la similitud que presenta con un huevo frito. Es decir, conserva algo de su primitiva esfera, pero buena parte de su masa se ha aplastado de forma considerable expandiéndose hacia el exterior (fig. 11, 9; fig. 12, F). Ello se debe a que en el momento del impacto, el plomo llevaba tanta velocidad -gran 
cantidad de energía cinética- que al impactar contra un cuerpo impenetrable, como la roca por ejemplo, elevó repentinamente su temperatura y se ablandó esparciéndose en torno al núcleo. Con los datos ya citados del test de Graz, se parte de la suposición de que este tipo de impactos podrían corresponder a disparos realizados a una distancia probablemente inferior a los $25 \mathrm{~m}$. Hay algunos ejemplares que conservan toda su masa, en especial los del diámetro $17,5 \mathrm{~mm}$. Pero en la mayoría de los casos han sufrido pérdida de sustancia.

\section{TIPO 6. PROYECTIL DEFORMADO TORTILLA}

$\mathrm{Al}$ igual que el Tipo 5, este grupo se caracteriza por presentar una forma peculiar y fácil de reconocer. Pero en este caso, la forma esférica ha desaparecido por completo. Si el grupo anterior fue relacionado con disparos a corta distancia, éste habría que asociarlo con disparos a muy corta distancia e incluso a quemarropa. La velocidad que llevaban estos proyectiles al impactar contra la roca, debió ser tal que perdieron por completo su forma original, volviéndose una masa amorfa de escaso espesor y similar a una tortilla (fig. 12, G). La mayoría de estos

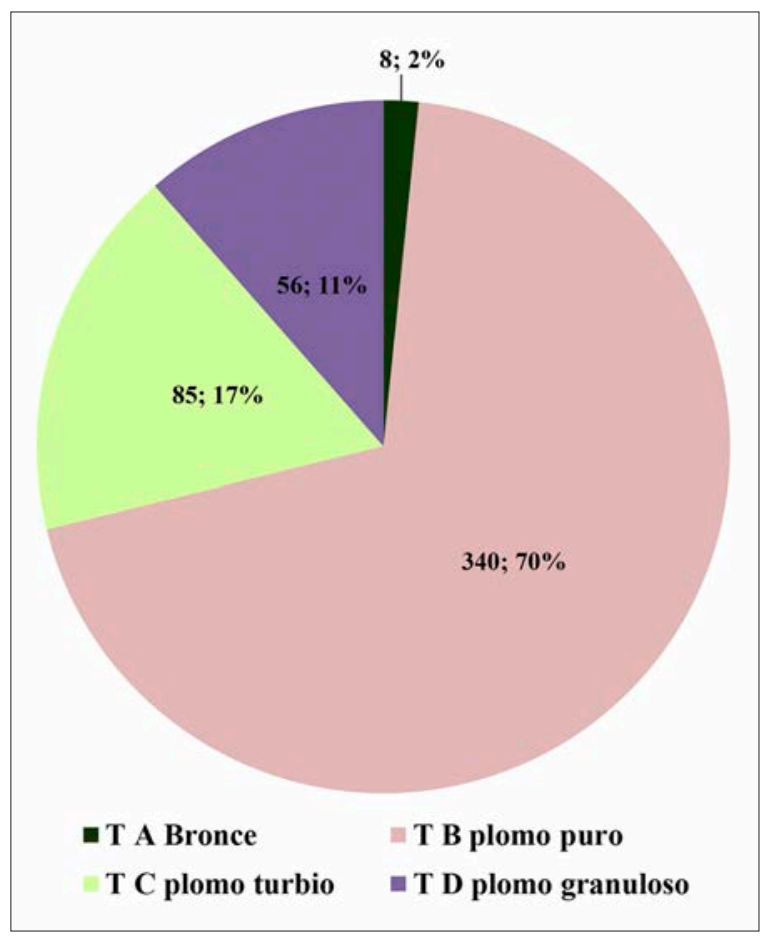

Fig. 13: Cantidad de proyectiles recuperados según el tipo de metal de su composición, determinado por observación visual. Ilustración del autor. hallazgos presentan un severo aplanamiento, con un espesor de entre 3 y $5 \mathrm{~mm}$, siendo muy pocos los que llegan a los $9 \mathrm{~mm}$. En casi todos estos ejemplares es posible distinguir el punto de impacto del proyectil, pues a partir del mismo surgen líneas radiales divergentes hacia el exterior. Con semejante violencia en el impacto es muy probable que el proyectil sufriera pérdidas de masa en forma de esquirlas. A tenor de lo expuesto anteriormente al tratar el test de Graz, es indudable que estos disparos se realizaron a muy corta distancia, probablemente a menos de $15 \mathrm{~m}$.

Hay que destacar que se trata de un conjunto bastante numeroso, en el que se incluyen 59 piezas. Lo cual resulta significativo y quizá indicador de una extremada violencia durante el episodio bélico, con abundantes disparos a muy corta distancia. Algo que, según el parte del general O’Donnell, efectivamente ocurrió durante una carga a la bayoneta: Dificilmente pueden ofrecerse ejemplos de una resolución más decidida que la que ostentó el batallón de Almansa en esta carga en que sufrió a muy corta distancia un fuego muy nutrido: ni una sola hilera vaciló, ninguna detuvo su marcha. (DMV 7-VIII-1839).

\section{TIPO 7. PROYECTIL FRAGMENTADO: ESQUIRLAS}

Otro conjunto de hallazgos, también muy numeroso -62 piezas- lo constituyen aquellos restos que se pueden calificar como esquirlas de proyectiles. La mayoría de ellas no alcanzan los $10 \mathrm{~g}$ de peso y presentan un espesor de entre 2 y $7 \mathrm{~mm}$ (fig. 11, 11). No tiene sentido calcular su diámetro teórico pues resulta evidente que se trata de fragmentos. Sin embargo, sí se ha considerado oportuno poner esta dimensión -el espesor o aplanamiento- en relación con T5 y T6. Tal y como se ha indicado, en estos grupos había evidencias de que algunas piezas podían haber sufrido pérdidas de materia, lo cual debió generar muchas esquirlas.

\section{OTROS TIPOS}

Además de los tipos ya expuestos, se han identificado otros conjuntos que, por razones de espacio, tan solo se citarán. En concreto hay piezas que han sido martilleadas de manera intencionada (fig. 11, 12). También las hay que muestran evidencias de haber sido mordidas o masticadas (fig. 11, 13), tema muy tratado en la bibliografía ${ }^{10}$. Algunos proyectiles presentan claras señales de haber estado expuestos a intenso fuego o incendio, hasta el punto de haberse derretido (fig. 11, 14). Y también los hay que muestran improntas de tela, reconociéndose con claridad la trama y la urdimbre del tejido (fig. 11, 15). 
Fig. 14: Resultados de las pruebas de densidad metálica sobre algunos proyectiles. Ilustración del autor.

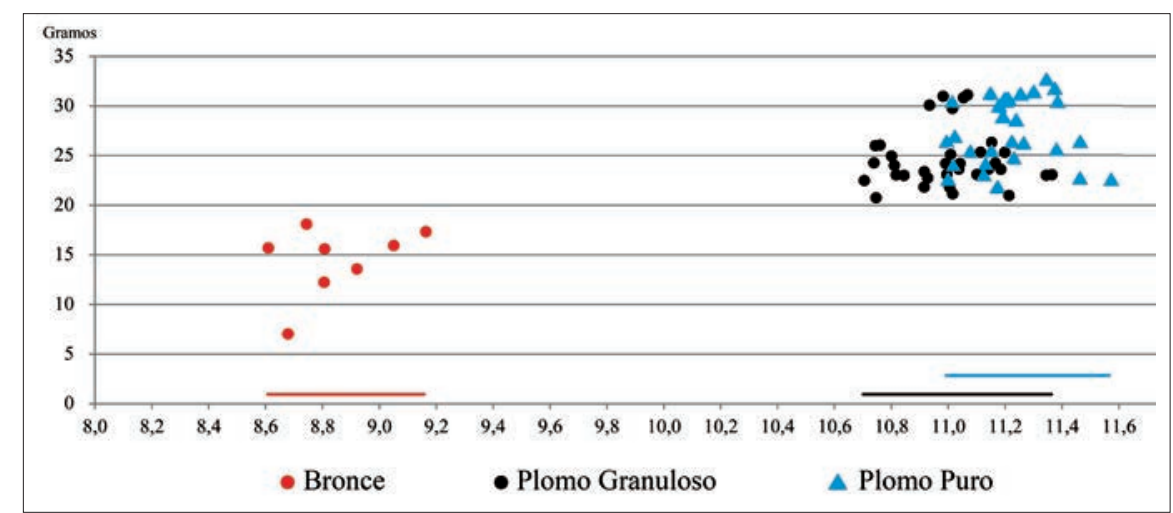

\section{CLASIFICACIÓN DE LOS PROYECTILES POR SU COMPOSICIÓN}

Dentro de los casi 500 proyectiles relacionados con la batalla carlista documentados en la sierra de la Cruz, algunos de ellos no son de plomo, sino de bronce. Algo verdaderamente singular ${ }^{11}$. Pero incluso entre los de plomo, se aprecian también ciertas diferencias respecto al material de su composición. Por eso, una de las clasificaciones establecidas atiende a su composición metálica. Hubiera sido ideal poder realizar análisis de difracción de rayos $\mathrm{X}$, de espectrometría y de microscopía metalográfica para conocer con exactitud su verdadera composición. Pero dada la imposibilidad de financiarlos, pues esta investigación no ha recibido ningún tipo de beca, ayuda pública o subvención, por desgracia hubo que limitarse a dos tipos de pruebas: la observación visual de la superficie y el análisis de la densidad metálica. La observación superficial ha dado como resultado una división en cuatro grupos: A de bronce; B de plomo puro; C de plomo turbio y D de plomo granuloso. Como se aprecia en la Figura 13 , el conjunto más abundante es el tipo B que casi representa las tres cuartas partes de los hallazgos.

En cuanto a la prueba de densidad, cuyos resultados se muestran en la Figura 14, permiten sospechar que los proyectiles de bronce podrían pertenecer a diferentes coladas. Las fuentes documentales indican que los carlistas, para fabricar sus cañones y morteretes empleaban el bronce de campana, cuyo peso específico es 8,81 mientras que el bronce de cañones llega hasta 9,23. De igual forma, aquellos proyectiles que denominamos de plomo granuloso tienen, en general, una densidad inferior al resto. Dado que el plomo sólido tiene un peso específico de 11,37 parece probable que estos proyectiles de aspecto granuloso, podrían estar aleados con estaño ${ }^{12}$.

\section{TIPO A. DE BRONCE}

Los proyectiles de bronce que se han recuperado ascienden a ocho ejemplares. Seis de ellos de tendencia esférica, uno fragmentado por la mitad y otro al que le falta una porción. Destacan del resto por varios motivos. Tal como se aprecia en la Figura 15, presentan una coloración muy diferente; son de un diámetro más reducido que la mayoría y, sobre todo, pesan menos que los de plomo de igual dimensión. A excepción de los dos que están incompletos, probablemente debido a rotura por impacto, en el resto resulta difícil discernir si fueron disparados o no.

Lo que sí resultan muy evidentes (fig. 16) son las marcas superficiales producidas durante el proceso de fabricación. Es posible reconocer un bebedero superior y otro inferior, así como una amplia costura del molde. Ello permite afirmar que fueron fundidos utilizando moldes bivalvos para múltiples proyectiles similares al de la Figura 17 y que el bronce líquido fluía del primero al último a través de los bebederos. También que, una vez enfriados y extraídos de los moldes, los proyectiles fueron sometidos a varios procesos. Primero corte para individualizar cada esfera y luego un proceso de acabado en el cual se eliminaron los bebederos y costuras sobrantes. Bien por medio de una lima de hierro o, lo que a tenor de las marcas parece más probable, mediante muela giratoria de piedra. Lo que permite suponer que la producción de estos proyectiles era muchísimo más lenta que en el caso de las municiones de plomo. Todos ellos, además, se caracterizan por una evidente imperfección esférica. No sólo a causa de las dificultades que ofrece la dureza del bronce para su acabado, sino también porque hay grandes diferencias entre sus diámetros, tanto sobre la junta del molde como a $90^{\circ}$ de ella. Esto sugiere que las paredes de los moldes estaban muy desgastadas -probablemente por exceso de uso-, y al juntar ambas mitades la falta de molde 


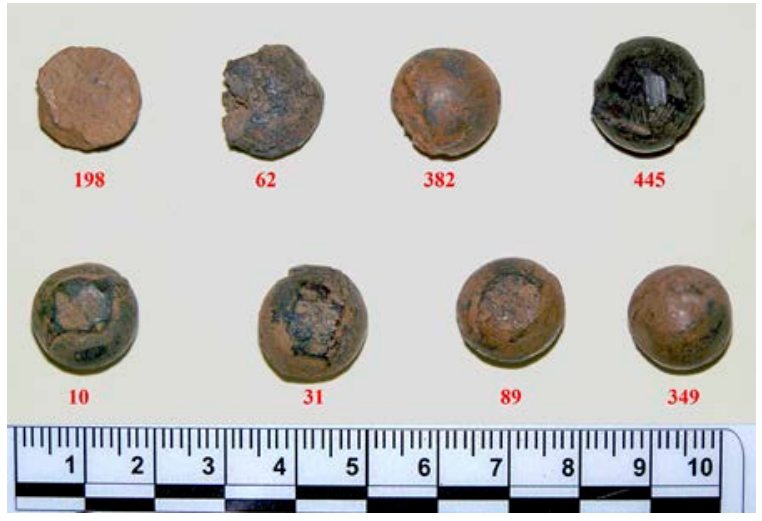

Fig. 15: Proyectiles de bronce recuperados en la Sierra de la Cruz. Fotografía del autor.
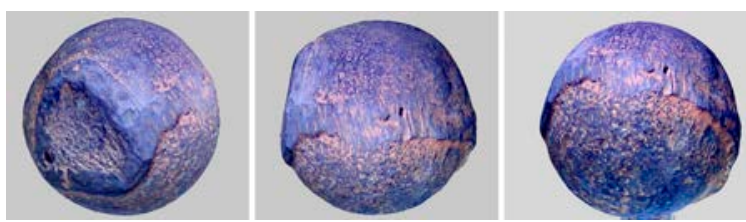

Fig. 16: Modelo fotogramétrico del proyectil de bronce $\mathrm{n}^{\circ} 10$. Izquierda: marca triangular correspondiente al bebedero superior, por donde entraba el bronce fundido al molde. Centro: el modelo se ha girado hacia la izquierda y se aprecia el perfil plano del bebedero y también la amplia costura del molde. Derecha: modelo girado hacia arriba, donde se observan las líneas dejadas por la herramienta empleada para desbastar la costura, mediante limadura o abrasión con grano fino. Se aprecia la desigualdad de $1 \mathrm{~mm}$ entre la parte superior y la inferior de la costura. Ilustración del autor.

favorecía que las dos partes se acercaran más de lo debido, provocando así una incompleta esfericidad -achatamiento- de las piezas fundidas.

Como ya se indicó anteriormente, la fórmula de la energía cinética establece que la masa del proyectil influye directamente en la velocidad del mismo $\left(1 / 2 \mathrm{~m} \cdot \mathrm{v}^{2}\right)$. Además, la resistencia que opone el aire es inversamente proporcional al peso del proyectil (De Luis 1990: 320). De todo ello puede concluirse que a estos proyectiles de bronce, lo reducido de su masa les limitaba muchísimo en alcance mientras que su evidente imperfección y falta de esfericidad, les privaban por completo de precisión. Sin olvidar el serio desgaste que causarían en el interior del cañón del arma que los disparaba.

Por todo ello, resulta indudable que estos proyectiles sólo podrían ser útiles a muy corta distancia o a quemarropa, siempre por debajo de los $10 \mathrm{~m}$, y que no eran lo más adecuado para enfrentarse a un enemigo que podía disparar desde mucho más lejos y con mayor precisión.

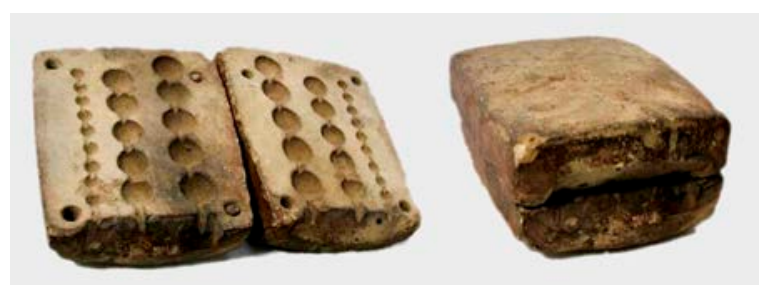

Fig. 17: Molde bivalvo para fundir proyectiles de varios diámetros. Los carlistas debieron emplear moldes similares para fabricar sus proyectiles de bronce. Fotografía: Ulrike, con autorización.

Ello explica lo reducido de su empleo, casi anecdótico, con tan solo el 1,2\% de los hallazgos.

Sin embargo, desde el punto de vista histórico, estos proyectiles resultan de una importancia capital. No sólo por su escasez y rareza, sino también porque pueden facilitar la interpretación del suceso bélico a la luz de la arqueología. A diferencia del resto de los proyectiles recuperados, con ellos se tiene la certeza de que sólo fueron empleados por uno de los bandos. El ya citado Wilhelm von Rahden afirma que en los primeros seis meses de 1838 la fundición de Cantavieja produjo más de 800.000 balas de fusil de bronce. Y que ...para suplir en lo posible la desventaja del menor alcance de las balas de bronce debido a su ligereza, determinó Cabrera que las tropas combatiendo en campo abierto fuesen abastecidas con balas de plomo, mientras que las que luchaban protegidas tras muros y parapetos lo fueran con balas de bronce. Estas últimas podían permitir que el enemigo se acercase a menor distancia de tiro (Von Rahden et al. 2013: 96).

Por tanto, su diámetro y su ubicación sobre el campo de batalla podrían facilitar la interpretación del resto de los hallazgos próximos.

\section{TIPO B. DE PLOMO PURO}

Constituyen el grupo más abundante, compuesto por 340 piezas. Estos proyectiles se caracterizan por ser de un plomo de color gris, tanto oscuro como claro, pero libre de impurezas a la vista e incluso brillante si se roza su superficie. En general, los proyectiles de este tipo que fueron disparados y resultaron impactados, parecen presentar una gran plasticidad, pues sus niveles de deformación tras el impacto, resultan muy acusados. La mayoría son balas bien terminadas, en las que casi no se aprecia ni la junta de molde ni del bebedero, posiblemente pulidas en barriles giratorios.

En muchas de ellas se aprecia la señal característica, similar a dos letras D opuestas y unidas (fig. 11,4) correspondiente a la marca que deja la herramienta empleada 
para recortar el bebedero. No obstante, aquellas que están sin disparar presentan a la vista un acabado tan excelente y perfecto que parecen haber sido fabricadas a máquina ${ }^{13}$. Por ello parece razonable suponer que la gran mayoría de este tipo de proyectiles fueron producidos a gran escala en alguna maestranza de artillería. Y por consiguiente que fueron empleados por las tropas del general O'Donnell. Sin embargo, dado que las tropas carlistas capturaban convoyes y hacían prisioneros a muchos soldados liberales, no se puede descartar que ellos también emplearan algunos de estos proyectiles fabricados por sus enemigos.

Dentro de este gran conjunto definido como plomo puro también se distinguen algunos ejemplares en los que se aprecia de forma muy acusada una ancha línea de molde. Esto implica que, además de estar desgastados los moldes, los proyectiles no fueron sometidos, o no el tiempo suficiente, al proceso de pulido general, que se realizaba mediante rotación dentro de un barril. Por tanto, podrían estar indicando una fabricación apresurada. Y en tal caso, es mucho más probable que estas piezas se relacionen con el bando rebelde que con el gubernamental (fig. 11, 3, 9 y 10).

\section{TIPO C. DE PLOMO TURBIO}

Otro de los conjuntos que se han podido diferenciar se caracteriza porque el metal presenta un color grisáceo de un tono más claro y apagado que el anterior. Donde más fácil resulta apreciarlo es sobre todo en los proyectiles impactados. Entre los elementos de este conjunto abundan las marcas de molde sin recortar, que son muy amplias y acusadas, como si apenas hubieran recibido tratamiento para su eliminación. A falta de análisis metalográficos, se parte de la hipótesis de que la diferencia de tonalidad podría ser consecuencia de alguna aleación de plomo con algún otro metal. Esta era una manera frecuente de incrementar la producción de balas en situaciones de escasez de plomo. En este sentido, sirva como ejemplo lo vivido por los propios habitantes de Lucena al estallar la guerra en 1833: Como escaseaban las armas y municiones, hombres, mujeres y niños se empleaban a fondo en limpiar las enmohecidas armas, formar cartuchos y hacer bolas derritiendo las pesas de reloj, platos, cubiertos y demás utensilios de plomo y estaño que se hallaban en las casas, porque todos estaban poseídos de un ardor y entusiasmo sin igual (Ortells y Nebot 1839).

Por ello, y por las acusadas marcas del molde, (fig. $11,9)$ inicialmente se decide atribuir el origen de estos proyectiles a las tropas carlistas.

\section{TIPO D. DE PLOMO GRANULOSO}

Por las mismas razones que las que se acaban de exponer, se considera este otro conjunto, muy característico a simple vista, como producido por los rebeldes carlistas. El plomo de estos proyectiles es también de un color gris claro, pero además se observan en su composición pequeños gránulos de color blanco. Su aspecto es muy similar al del proyectil de peltre que reproduce Sivilich y Miller (2016: 118). Al igual que el anterior grupo, también presentan marcas de molde muy acusadas. Algunos incluso destacan por su falta de esfericidad, apareciendo muy achatados (fig. 11, 7). También parecen presentar una resistencia superficial mayor y una menor plasticidad. Todo lo cual invita a sospechar que pueda tratarse de algún tipo de aleación en la que predomina el plomo. Cabe recordar que, de la misma manera que para fabricar los proyectiles de bronce los carlistas fundieron las campanas que habían robado en muchos pueblos de Castellón, no sería extraño que dedicaran al mismo fin, las tuberías de los órganos de algunas iglesias que, pocos días antes de la batalla de las Useras, habían desvalijado en su insaciable necesidad de metales ${ }^{14}$. El empleo de balas de estaño por los carlistas valencianos está confirmado por la fuentes literarias, tal y como recoge Lichnowsky, quien aprovecha, -igual que hiciera su compatriota von Rahden- para poner en evidencia la escasa formación, no ya científica, sino puramente militar, del caudillo rebelde: Las balas fabricadas con estaño de tuberías eran demasiado ligeras para la cantidad ordinaria de pólvora. Cabrera, poco familiarizado con las leyes de la gravedad, creyó que siendo la balas más ligeras, no había más que disminuir la cantidad de pólvora; pero cuando Moreno le hizo observar su error, mandó rehacer los cartuchos, diciendo que un general tan viejo debía entender más que él de estas materias (Lichnowsky 1942: 111).

\section{RESULTADOS Y DISCUSIÓN}

A tenor de todo lo expuesto resulta evidente que el estudio de tantos proyectiles, con las numerosas variables que presentan, resulta complejo. Atribuirlos a uno $\mathrm{u}$ otro bando no es algo tan sencillo como cuando se estudia la cartuchería metálica de producción industrial propia del s. XX. Para visualizar con mayor facilidad todas estas variables citadas y tratar de obtener así algunas conclusiones válidas, con fundamento científico y objetivo, se han empleado gráficas de dispersión. Para ello 
se presentan dos láminas con idénticas características. En cada gráfica el eje X representa el peso de cada bala, que puede variar desde los 32,65 gr de algún proyectil sin disparar, hasta los escasos dos gramos de algunas esquirlas. En el eje Y se mide el espesor o aplanamiento que conservan los proyectiles tras su impacto, salvo en el caso de los tipos TA, T1 y T2, en los que el espesor es el propio diámetro de las piezas. En todas las gráficas se han establecido dos bandas verticales en tono ocre, que delimitan dos franjas de peso. La primera entre los 23,5 y los $27 \mathrm{gr}$; la segunda entre los 28 y los 31,5 gr.

Dado que el peso de una esfera de plomo está directamente relacionado con su diámetro, conocer esta magnitud -que resulta más fácil de medir con precisión que el diámetro afectado por los impactos y deformaciones-, permite relacionar cada pieza con su correspondiente diámetro. Por tanto, dentro de estas franjas se encontrarían los dos principales calibres de las armas empleadas.

La Figura 18 Gráfica ${ }^{\circ} 1$ demuestra, en primer lugar, cómo los proyectiles de bronce -representados con triángulos oscuros-, tienen un peso muy inferior al de aquellos de igual diámetro realizados en plomo. Se observa también que en algunos de ellos sus diámetros son más reducidos, lo que probablemente significa que fueron usados en pistolas o en carabinas ${ }^{15}$. En la misma figura se representan, con círculos oscuros, los proyectiles sin disparar, cuyo diámetro es el que mejor se ha podido medir. En tono más claro se representan aquellos que, aunque fueron disparados, son tan leves sus deformaciones que también permiten registrar su diámetro. Precisamente es en estos casos donde puede reconocerse el error en la medida por su desviación respecto al peso.

El resultado de todo ello es muy revelador. Demuestra que, en la franja más oscura, entre 28 y 31,5 gr, hay una gran concentración de proyectiles sobre la línea de $17,50 \mathrm{~mm}$ de diámetro. Estas balas corresponden a las empleadas en armas de calibre $19 \mathrm{~mm}$, sin que puedan emplearse en otras armas de calibre inferior pues no entran en el cañón ${ }^{16}$. Este era el calibre de los fusiles británicos que, según las fuentes documentales, constituían la dotación de las tropas gubernamentales. En el Ejército del Centro todas las unidades estaban equipadas con fusiles tipo Brown Bess de calibre 0.75 de pulgada o 19,05 mm. Todo el material obsoleto o defectuoso había pasado a manos de la Milicia Nacional y de los Cuerpos Francos. Este calibre se denominaba en la época de a 15 en libra, porque de cada libra de plomo se obtenían 15 balas.
En la otra banda más clara y de inferior peso, la mayor concentración se produce sobre los 16,50 mm de diámetro. Sobre esa misma línea también coinciden dos proyectiles de bronce, que como ya se ha indicado, eran de uso exclusivo carlista. Por tanto, queda claramente diferenciada la existencia de otro tipo de armamento usado en gran abundancia pero de calibre inferior al británico. En concreto, se trata de armas del calibre $18 \mathrm{~mm}$. Este era el empleado por las armas reglamentarias españolas desde el s. XVIII, y denominado de a 17 en libra ${ }^{17}$. Dichos proyectiles también podían dispararse en los fusiles británicos, aunque su precisión y alcance fuera menor que con las balas de 17,50 mm. La coincidencia de varios proyectiles de bronce con dicho calibre induce a sospechar que buena parte de las tropas carlistas que participaron en esta batalla, estaban equipadas con fusiles españoles de calibre $18 \mathrm{~mm}$.

La Gráfica $\mathrm{n}^{\circ} 2$ engloba los hallazgos del Tipo 3 y Tipo 4. Piezas que han perdido ya su figura esférica a causa de los impactos y en las que no es posible medir con precisión su diámetro. Por tanto se sustituye esta dimensión por el espesor que presentan. Sin embargo, su peso sigue revelando el tipo de proyectiles que eran originalmente. Como puede comprobarse, a pesar de que algunos ya presentan claros indicios de pérdida de sustancia, muchos de estos elementos siguen situándose dentro de los dos calibres predominantes en la batalla.

La Gráfica $n^{\circ} 3$ engloba los tres tipos de hallazgos que estarían vinculados con disparos a corta y muy corta distancia. Por sus características deformaciones, tanto en el Tipo 5 como en el Tipo 6, resulta imposible medir su diámetro y las pérdidas de sustancia son muy evidentes. Pero a pesar de sufrir impactos tan violentos, algunos de ellos continúan dentro de la banda de peso que identifica exclusivamente la munición británica. Al mismo tiempo, la representación de las esquirlas documentadas -triángulos-, fruto de impactos y rebotes a distancias muy cortas, reflejan lo reducido de su tamaño y de su peso. Muchas de ellas se concentran entre los 4 y los 10 gr, y son la prueba evidente de la pérdida de materia en muchos proyectiles.

Todo esto, que no es poco, es lo que aporta el análisis de las deformaciones que presentan los proyectiles. Ahora, en cambio, se prestará atención al tipo de metal y a las marcas de fabricación.

La Figura 19 Gráfica ${ }^{\circ} 4$ representa dos clases de proyectiles. Los de bronce y aquellos calificados como plomo puro. De estos últimos ya se indicó en un apartado 
A corta distancia. Proyectiles esféricos de la acción de Las Useras, Castellón (17 de julio de 1839)
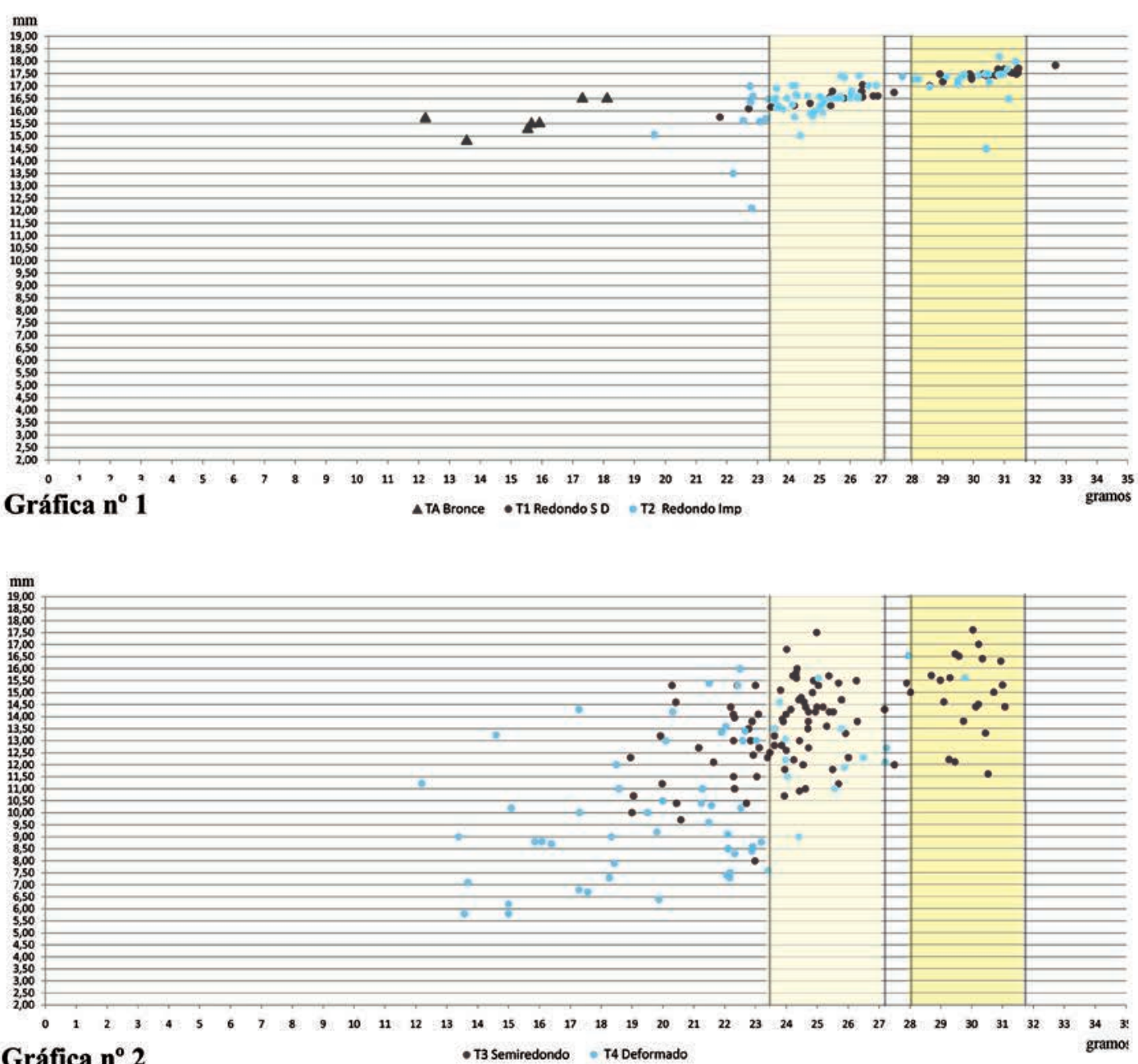

Gráfica $\mathbf{n}^{\circ} 2$

- T3 Semiredondo - T4 Deformado

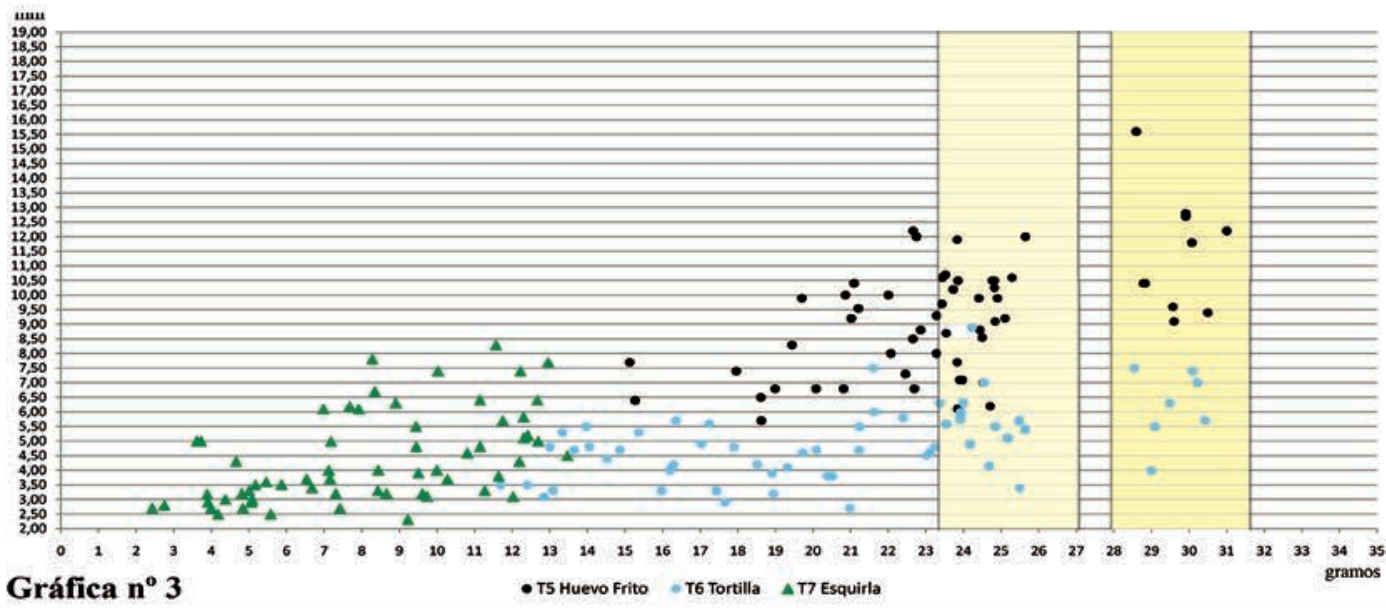

Fig. 18: Gráficas de dispersión X Y según el grado de deformación que presentan los proyectiles. Ilustración del autor. 


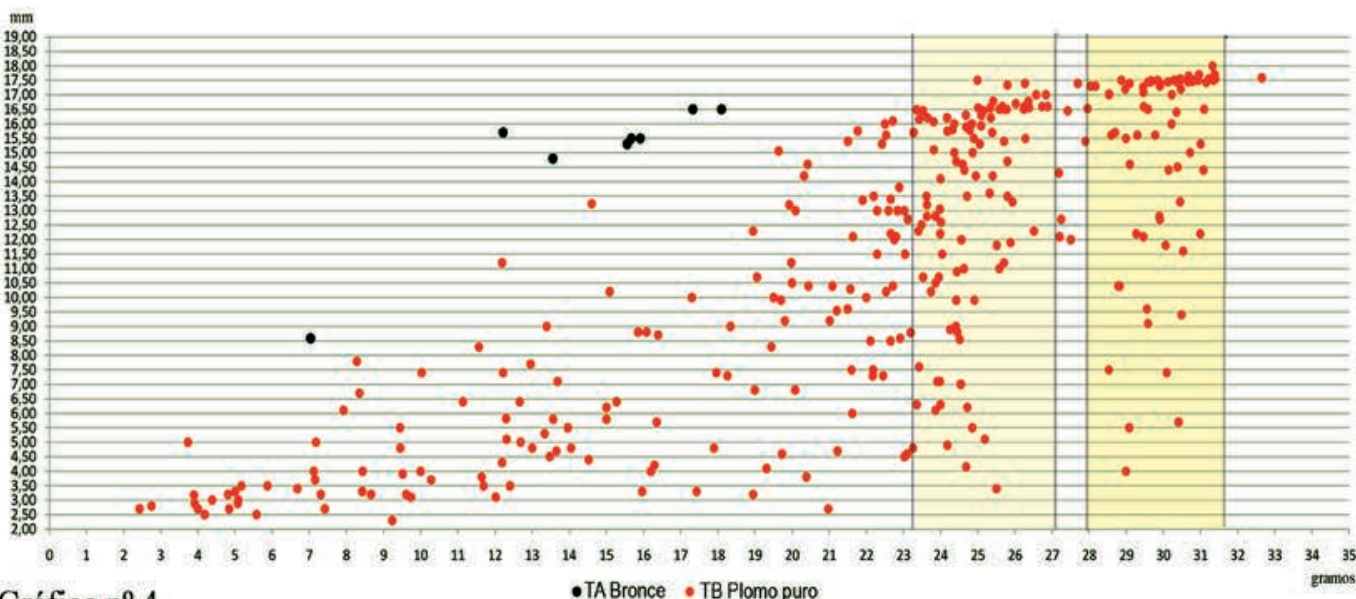

Gráfica $\mathrm{n}^{\circ} 4$

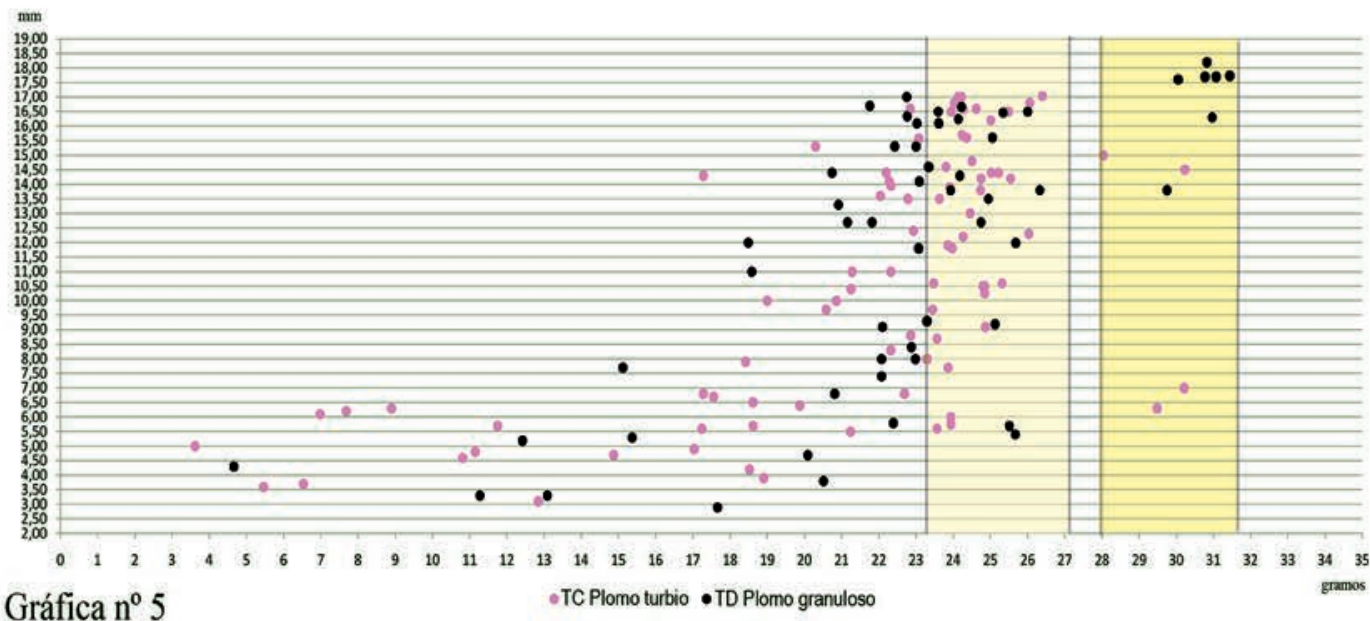

Gráfica ${ }^{\circ} 5$

-TC Plomo turbio •TD Plomo granuloso

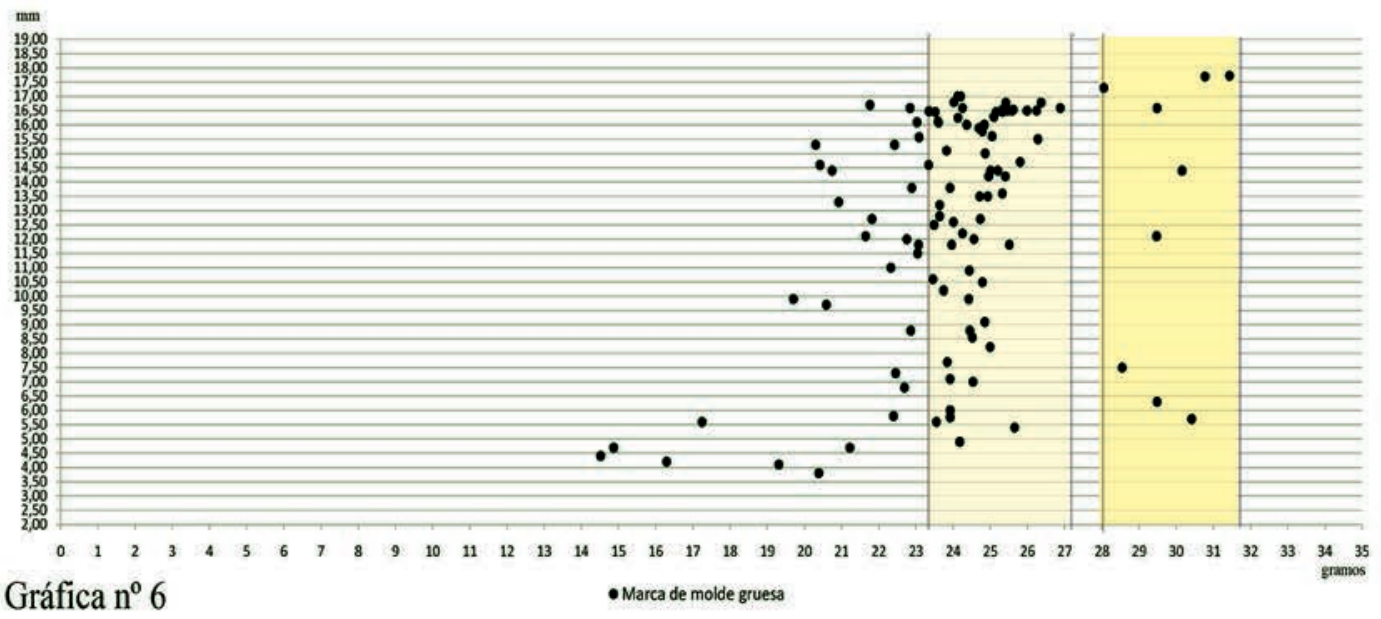

Fig. 19: Gráficas de dispersión X Y según la composición metálica y las marcas de molde que presentan los proyectiles. Ilustración del autor. 
anterior que parecían mostrar una mayor plasticidad en sus impactos. Ahora se reconoce con claridad que la mayoría de las esquirlas corresponden a este conjunto. También que en los dos calibres identificados se encuentran proyectiles de plomo puro.

La Gráfica $\mathrm{n}^{\mathrm{o}} 5$ representa los tipos C y D, a los que se denominó plomo turbio y plomo granuloso y en los que se sospecha la existencia de aleaciones de otros metales junto con el plomo. Se indicó también que presentaban menor plasticidad ante los impactos y de hecho el número de esquirlas de estos materiales es menor que el anterior. Aunque se reconocen algunos ejemplos del calibre británico, los del calibre español resultan mucho más abundantes.

Finalmente en la Gráfica $n^{\circ} 6$ se presentan aquellos proyectiles que muestran una línea de molde muy marcada, la cual se ha considerado indicio de fabricación apresurada y de mala calidad. Esta gráfica guarda una estrecha similitud con la anterior -pocos elementos del calibre británico y muchos del español- y evidencia un claro predominio de los proyectiles de $16,50 \mathrm{~mm}$ en el municionamiento de los carlistas.

De lo representado en las Gráficas $n^{\circ} 5$ y n ${ }^{\circ} 6$ se puede deducir que los carlistas fabricaron proyectiles para los dos calibres, si bien predominan los de diámetro de 16,50 $\mathrm{mm}$. También resulta evidente que hay una estrecha relación entre el plomo con aleaciones, la gruesa marca de molde tan característica y el calibre menor, empleado por los rebeldes durante esta batalla. Esto encaja con algunas referencias que transmiten las fuentes documentales. Por ejemplo, apenas un mes después de la batalla de las Useras, las tropas de Cabrera volvieron a ser derrotadas por el general O'Donnell en el sitio de Tales. Entre los efectos que los vencedores recuperaron dentro del semiderruido castillo figuran: 57 fusiles españoles e ingleses con sus bayonetas. Sin embargo, en el mismo inventario, las municiones citadas sólo pertenecen a un calibre: 26.400 cartuchos de fusil españoles $^{18}$. Lo cual indicaría que los
Fig. 20: Determinación del diámetro en proyectiles de bronce y no disparados, y cantidad recuperada de cada uno de ellos. No se incluyen los dos de bronce fragmentados. Ilustración del autor.

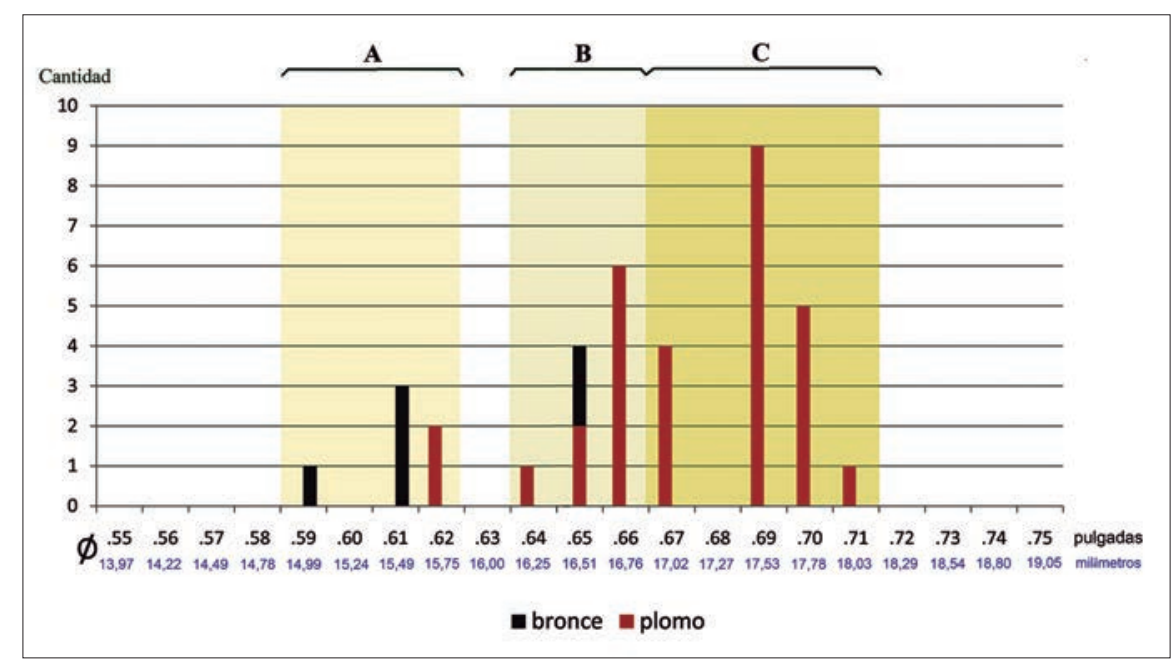

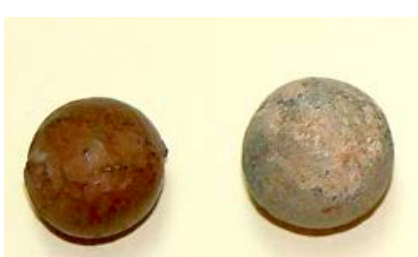

A

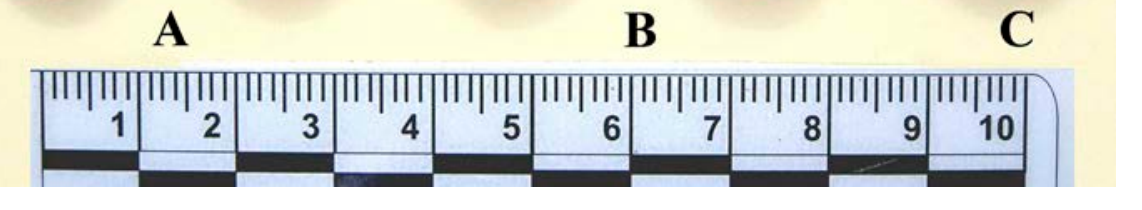

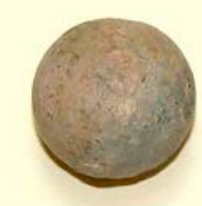
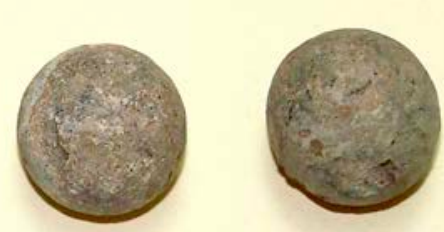

C

B
Fig. 21: Proyectiles representativos de los tres calibres identificados en la fig. 20. Fotografía del autor.

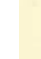

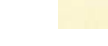




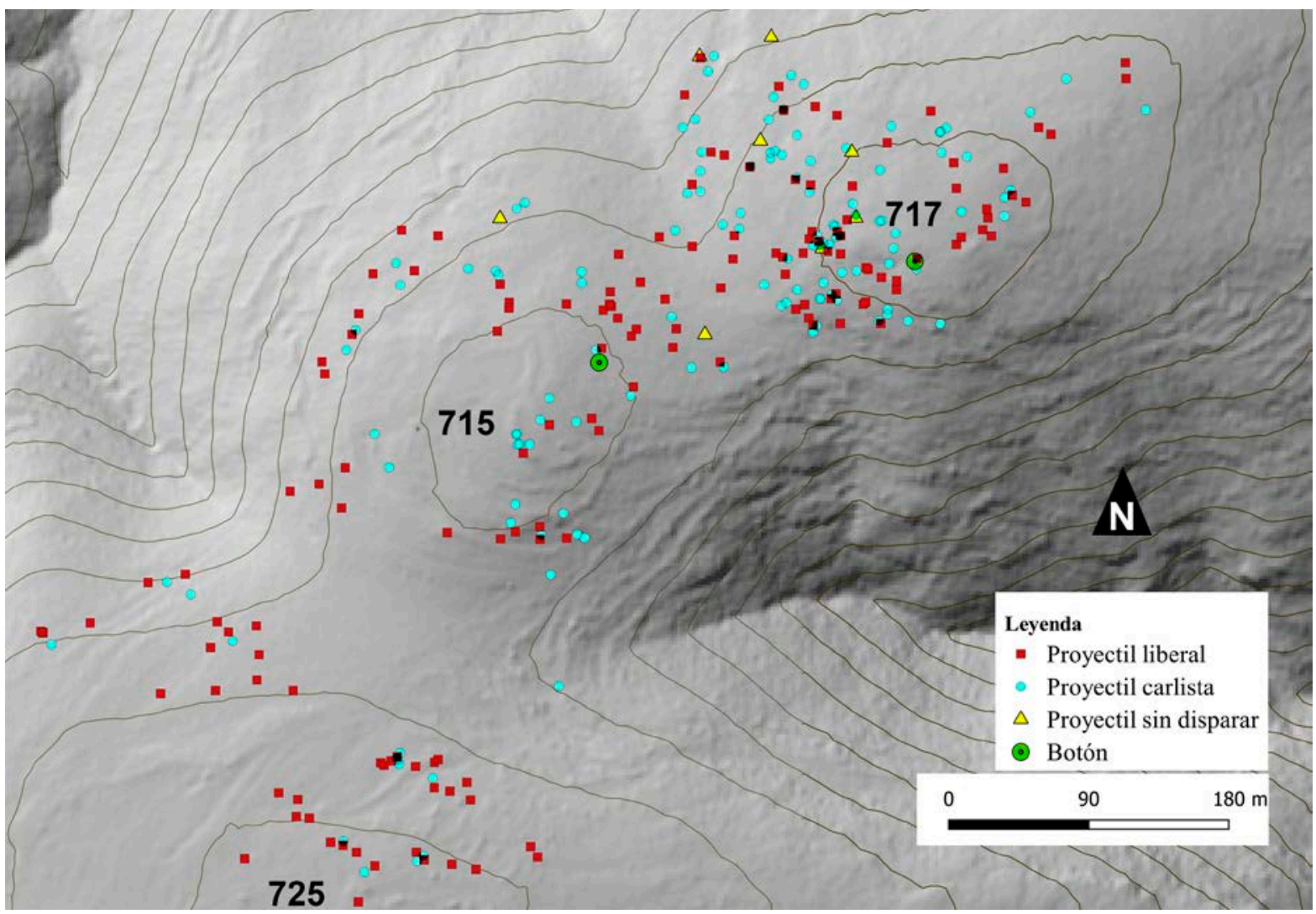

Fig. 22: Ampliación de las cotas 715 y 717. La concentración de proyectiles y su alto grado de deformación evidencian que fue aquí donde ocurrió la fase más violenta de la batalla. Se han agrupado como carlistas los de bronce, plomo turbio, plomo granuloso y los que presentan gruesas líneas de molde. Ilustración del autor.

carlistas valencianos resolvieron el problema de usar dos calibres distintos de una manera muy pragmática: fabricar una munición que pudiera dispararse en ambos. Es decir, el proyectil más pequeño, el de $16,50 \mathrm{~mm}$. Algo que ya en 1833 el Prontuario de Artillería, explicaba así: ...con el fusil inglés pueden tirarse balas inglesas, espanolas y francesas; y aunque con estas dos especies últimas, por el mucho viento, resultará incertidumbre en los tiros, como la puntería de la tropa es tan poca exacta, no serán demasiado sensibles las desventajas. (Se supone que esto es para cuando no hay otra cosa). El fusil español puede tirar balas españolas y francesas. El francés, francesas solamente (De Salas 1833: 33). A esto era, precisamente, a lo que nos referíamos al analizar el Tipo 2, apartado b.

A tenor de lo observado en las gráficas de dispersión que se acaban de presentar, ya es posible tener una básica idea de los calibres empleados durante la batalla. Se han identificado claramente dos de ellos, en concreto el de a
15 en libra y el de a 17 en libra. Además, las dimensiones de algunos proyectiles de bronce, parecen indicar la existencia de algún otro todavía más reducido, de a 19 o de a 20 en libra. Con objeto de verificar estas sospechas se ha realizado un gráfico para compararlos con aquellos proyectiles que no fueron disparados. El resultado permite asegurar que fueron empleadas armas de pequeño calibre, probablemente pistolas, cuya munición identificamos con el grupo A en las Figuras 20 y 21.

\section{CONCLUSIONES}

La Acción de las Useras fue uno de los combates más sangrientos de la Primera Guerra Carlista ocurridos en la provincia de Castellón. En las escasas ocho horas que duró el episodio, ocurrido en campo abierto y sin intervención de la caballería -arma mortífera por excelencia-, el bando gubernamental sufrió 207 heridos, 53 contusos 
y 41 muertos directos. Éstos últimos fueron inhumados en el propio campo de batalla, según consta en los libros sacramentales de los batallones.

Con apenas 14 días de prospección, se han delimitado sobre el campo de batalla zonas de gran concentración de proyectiles, que parecen indicar el lugar donde ocurrió la acción más violenta. Allí donde las bayonetas de las tropas liberales, formadas en columna cerrada y sufriendo descargas a muy corta distancia, rompieron la voluntad defensiva de los carlistas obligándoles a abandonar sus posiciones y correr hacia el monte Gozalvo.

Mediante el SIG podemos representar cada proyectil según sus atributos de forma, peso, metal o tipo de impacto, lo cual ofrece una imagen más esclarecedora de la batalla, tal como puede apreciarse en la Figura 22. La información que aportan estos hallazgos arqueológicos es totalmente objetiva y no está condicionada por sesgos y tendencias ideológicas, tan frecuentes cuando se estudian las guerras civiles en España.

La munición empleada por las tropas carlistas refleja una clara necesidad de renovar su armamento y más después de seis años de guerra. También pone de manifiesto lo mucho que afectó a los rebeldes el apresamiento del buque Gulnave, cinco meses antes, cargado con 10.000 fusiles británicos en las cercanías de Vinaroz. Semejante pérdida les obligó a continuar usando sus desgastadas armas del calibre de a 17 en libra.

Muchos proyectiles demuestran, por su mala calidad, que todavía en 1839 los rebeldes seguían sufriendo problemas de abastecimiento de metales. El empleo de balas de bronce no es ningún avance tecnológico, sino un síntoma de penuria. Los materiales analizados apuntan a que, en la producción de balas, priorizaron la cantidad sobre la calidad, con pésimos niveles de acabado. Algo que quizá no les importaría demasiado si las iban a emplear en armas de un calibre superior. Sin embargo, con semejantes proyectiles, el alcance y la precisión de sus disparos se verían muy afectados y, sin duda, serían inferiores a los de sus contrarios. Por ello, necesitarían que el enemigo se acercara mucho para hacer fuego a corta y muy corta distancia.

En toda guerra, la propaganda es un arma más y la verdad, la primera de las víctimas. Cabrera, en su parte oficial, trató de ocultar las bajas sufridas y solo reconoció siete muertos y 114 heridos (De Córdoba 1845: IV, 477). Pero su propio comandante de Ingenieros elevó las bajas a 700 (Von Rahden et al. 2013: 432). Cifra que coincide con varios testimonios aparecidos en la prensa liberal valenciana. Parece lógico que en retirada y huyendo, como afirmó O'Donnell en el parte oficial, las pérdidas de Cabrera fueran muy superiores a las de los liberales, pues...los soldados mueren en grandes cantidades cuando huyen, porque es mostrando la espalda al enemigo cuando son menos capaces de defenderse a sí mismos (Keegan 1990: 82).

La sierra de la Cruz, no solo acoge los restos de numerosos soldados republicanos muertos en junio de 1938, sino también los de decenas de liberales y carlis$\operatorname{tas}^{19}$. Por eso confiamos que en un futuro no lejano, y al igual que se hace en otros países occidentales, contemos con los recursos y las voluntades necesarias para investigar metódicamente este campo de batalla. Un terreno que, a nuestro parecer, ha sido transcendental en la historia reciente de la provincia de Castellón.

\section{NOTAS}

1. El hecho de que a Ramón Cabrera se la denominara el Tigre del Maestrazgo, obedece a su crueldad extrema. Algo que no sólo relataron sus contrarios sino hasta sus propios seguidores. Las memorias inéditas del coronel carlista Cayetano Gómez describen, entre otras lindezas, cómo Cabrera ordenó descuartizar a un proveedor de aguardiente atando sus miembros a cuatro caballos y azotándolos después para que salieran a galope.

2. Para el UK Battelfields Recourse Center véase www.battlefieldstrust.com.

3. Autorización arqueológica de la Generalitat Valenciana $\mathrm{n}^{\circ}$ 2012/0040-Cs.

4. Los resultados de la primera prospección disponibles en González (2014; 2015), y los de la segunda, relativos a la actividad bélica de 1938 en González (2017).

5. Autorización arqueológica de la Generalitat Valenciana $n^{\circ}$ 2014/331-Cs.

6. En 1838 ...coincidiendo con el establecimiento de fuerzas de Artillería de montaña con carácter permanente, el cañón de montaña de 4 libras fue sustituido por un modelo de obús corto de 5 pulgadas (Calvó 2014: 19).

7. Para estimar el consumo de cartuchos partimos de la consideración que en la zona prospectada fue donde actuó una de las dos divisiones de O'Donnell, la Primera, la cual consideramos en cifras redondas de 5.000 hombres. De los 4.150 efectivos que Cabrera había reunido para asediar Lucena del Cid dejó en el bloqueo dos batallones -unos 700 hombres- y otros tantos para defender la izquierda del camino. Por tanto, sobre la sierra de la Cruz habría unos 3000 carlistas enfrentados a los 5000 liberales mandados por Azpiroz. Sabemos que en el 
ejército del Centro cada batallón lo formaban ocho compañías de las que seis eran de fusileros y dos de preferencia-cazadores y granaderos o tiradores y carabineros-. Las de preferencia estaban municionadas a 50 cartuchos por plaza, pero para simplificar el cálculo redondearemos a la baja, como si todos los soldados liberales fueran fusileros dotados con 40 cartuchos. De manera que, suponiendo que los 8000 combatientes consumieran sus 40 cartuchos, obtendríamos 320.000 disparos. Puede parecer una cantidad muy elevada, pero incluso reduciendo la cifra a solo 5000 combatientes y que cada uno realizara 10 disparos el resultado serían 50.000 proyectiles consumidos. Hay que señalar que Cabrera justificó su retirada, como en otras ocasiones en las que fue derrotado, en haber consumido todas sus municiones. Si después de tres semanas acantonado en torno a Lucena, Cabrera no tuvo ocasión de acumular municiones para la previsible batalla que tendría que librar, es que quizá no era tan gran líder militar como algunos se esfuerzan en representar.

8. Dauriac (2011: 103-116) recoge las numerosas experiencias técnicas que se realizaron al finalizar las guerras napoleónicas, destinadas a conocer el alcance y eficacia de los principales fusiles de la época.

9. The live fire experiments were designed to capture information of flintlock firearm performance and capabilities that will benefit the goal audiences in their understanding and interpretation of archaeologically recovered spherical lead balls. To achieve these objectives, we designed the experiments to collect data on: 1) the velocity, range, and ballistic performance of common spherical lead balls of the type used in the Colonial era. 2) factors that could cause variation in ball impact, and 3) how deformation of lead balls can be linked to velocity, impact range, and target media (Scott et al. 2016: 2).

10. Sobre las balas mordidas hay un amplio debate en la bibliografía internacional. En el proyecto que el autor de este artículo lleva a cabo en Gallegos de Argañán, Salamanca, casi un 20\% de los proyectiles documentados aparecen con señales de mordeduras por animales (González 2018: 234). Daniel Sivilich (2016: 167) presenta imágenes de mandíbulas de cerdos salvajes con abundantes restos de plomo entre sus molares.

11. Dentro de la propia historia bélica española se conocen diversos casos en los que la necesidad obligó a producir proyectiles para fusil en materiales poco frecuentes. Así, en el s. XVII, la guarnición guipuzcoana de Fuenterrabía se defendió disparando balas de plata y en Manresa, durante la Guerra de la Independencia, a falta de plomo los herreros fabricaron gran cantidad de balas de hierro (De Salas 1833: 86).

12. El análisis de la densidad se realizó a una muestra representativa de los tres principales tipos, mediante el método de inmersión en agua y sobre balanza electrónica de alta precisión, a una temperatura ambiente de $25^{\circ} \mathrm{C}$.

13. Ya se fabricaban balas de fusil mediante prensado en frío, gracias a la máquina inventada por Napier, que incluso llegó a ofrecérsela al rey Fernando VII poco antes de su muerte.
14. En enero de 1838 los rebeldes carlistas arrancaron y se llevaron los tubos del órgano de la iglesia de Torreblanca (ADPCs 23-I-1838). Y el 3 de julio de 1839 robaron las flautas de los órganos de las dos parroquias de Vall de Uxó (DMV 9-VII-1839).

15. En el estudio que Calvó (2004) dedica al armamento militar de avancarga, las únicas piezas que presentan un calibre de boca de $16 \mathrm{~mm}$ son pistolas. En concreto los ejemplares 2C, 9C, $11 \mathrm{C}, 45 \mathrm{C}, 46 \mathrm{C}, 53 \mathrm{C}, 54 \mathrm{C}$ y $55 \mathrm{C}$. Por su parte el $47 \mathrm{C}$ corresponde también a una pistola, pero de calibre de boca $16,5 \mathrm{~mm}$.

16. Conviene recordar que el calibre se emplea exclusivamente para referirse a la boca del arma. En los proyectiles lo que se mide es su diámetro.

17. En el citado estudio de Calvó (2004), se recogen 4 carabinas, 3 escopetas, 3 mosquetones, 8 tercerolas, 18 fusiles, y 47 pistolas que empleaban este calibre, todos ellos modelos fabricados desde el año 1789 hasta 1836.

18. (DMV 30-VIII-1839). Cuando el general Espartero tomó el fuerte de Segura a los carlistas, se recuperaron en su interior 51 fusiles españoles y 52 ingleses y para municionarlos 20.000 cartuchos del calibre español y 40.000 del inglés (EEC 10-IV-1840).

19. La prospección permitió documentar también tres inhumaciones superficiales, probablemente de soldados muertos en 1938, así como diversos puntos donde se sospecha pueden existir más enterramientos. Todos ellos, a día de hoy, sin excavar (González 2017: 239-241).

\section{BIBLIOGRAFÍA}

ADPCS, Archivo Diputación Provincial de Castellón. Actas de Gobierno.

ARÉVALO, R. (2010): Episodi bél.lic de la Primera Guerra Carlina a Albaida, III Jornades d'arqueologia de València i Castelló: Museu d'història de València, 10-12 de desembre 2010, València, 195-206.

AZPIROZ, F. J. (1842): Memoria del general D Francisco Javier de Azpiroz sobre la última campaña de la Primera División del Ejército del Centro, Madrid.

CABELLO, F.; SANTA CRUZ, F.; TEMPRADO, R. M. (2006): Historia de la guerra última en Aragón y Valencia, Zaragoza.

CALBO Y ROCHINA DE CASTRO, D. (1845): Historia de Cabrera y de la Guerra Civil en Aragón, Valencia y Murcia, Madrid.

CALVÓ, J. L. (2004): Armamento de munición en las Fuerzas Armadas españolas. Producción de antecarga, 1700-1873, Barcelona.

CALVÓ, J. L. (2014): Artillería de ordenanza en el Ejército y la Armada españoles 1728-1935, Barcelona.

CASTILLO, R. DEL (1860): Historia de la vida militar y política del Excmo. Sr. Capitán general D Leopoldo O'Donnell, Madrid. 
CLONARD, S. M. DE SOTO Y ABBACH, CONDE DE (1851): Historia orgánica de las armas de Infantería y Caballería españolas desde la creación del Ejército permanente hasta el día. VI, Madrid.

CNIG, CENTRO NACIONAL DE INFORMACIÓN GEOGRÁFICA: BTN25_ETRS_BCN0507S

DAURIAC, E. (2011): Les armes de Napoleón. Balezy, Isle

DE CÓRDOBA, M. B. (1845): Vida militar y política de Cabrera. IV, Madrid.

DE LUIS TURÉGANO, J. V. (1990): Policía Científica. Técnica policial, V II, València.

DE SALAS, R. (1833): Prontuario de artillería para el servicio de campaña, Madrid.

$D M V$, Diario Mercantil de Valencia.

EEC, El Eco del Comercio.

ESCRIG, J. (1998): Llucena una historia de L’Alcalatén: sociedad, poblamiento y territorio, Castelló de la Plana.

FAUS, A. (2016): Cartografía de la Primera Guerra Carlista. Planos del frente del Maestrazgo del capitán Manfredo Fanti (1837-1840), Saitabi 66, 141-162.

GALLUSSER, A.; BONFANTI, M.; SCHULZ, F. (2002): Expertise des armes à feu et des éléments de munition dans l'investigation criminelle, Lausana.

GARCÍA-MUNICIO DE LUCAS, E. I. (2018): Militares y Masonería. Tesis doctoral. Universidad Complutense de Madrid.

GONZÁLEZ GARCÍA, C. (2014): Prospección Arqueológica de un campo de batalla, el vértice Gozalvo, Lucena del Cid, Castellón.

GONZÁLEZ GARCÍA, C. (2015): Prospección arqueológica de un campo de batalla. El Vértice Gozalvo, Lucena del Cid, Castellón, Sagvntvm-PLAV 47, 233-248. DOI: https://doi.org/10.7203/SAGVNTVM.47.4990

GONZÁLEZ GARCÍA, C. (2017): Combates en la Serra de la Creu, junio de 1938 (Llucena, Les Useres, Atzeneta del Maestrat), La Linde 8, 219-247, <http://lalindearqueologia.com/ wp-content/uploads/2017/03/08-Combates-Serra-Cruz_ CGonzalez.pdf>.

GONZÁLEZ GARCÍA, C. (2018): Campos de Batalla en Gallegos de Argañán, Salamanca, ss. XVII-XIX. Primera fase, Sagvntvm-PLAV 50, 219-240, Valencia.

DOI: https://doi.rg/10.7203/SAGVNTVM.50.12294

GONZÁLEZ GARCÍA, C. (2020): Franceses contra británicos en el puente de Marialba. Historia y arqueología de un episodio de la guerra de la independencia en Gallegos de Argañán, Salamanca, Gladius XL.

DOI: https://doi.org/10.3989/gladius.2020.08

GUIRAO, R. (1999): Botones Españoles de Uniforme, Madrid.

GUIRAO, R.; MACÍAS, F.; MILIÁN M. A. (2013): Botones de uniforme. España, 1791-2011, Montpellier.

HOCKENSMITH, C.; FIEGEL, K.; FREELS, R. (2000): Civil war era chewed bullets from Kentucky: battlefields anesthesia or other activities? Ohio Valley Historical Archaeology 15, 100-113.
HOMANN, A. (2013): Battlefield Archaeology of Central Europe, with focus on Early Modern Battelfields, Historical Archaeology in Central Europe, Rockville.

HUISMAN, D. J.; VAN DOESBURG, J.; VAN OS, B. J. H.; KROEZE, A.; MOOREN, S.; KNIEP, J. (2012): Bullets over Gennep. Using compositional variation in lead musket balls in battelfields archaeology, Ministry of Education, Culture and Science, <https://www.academia. edu/6793493/D.J._Huisman_J._van_Doesburg_B.J.H._ van_Os_A._Kroeze_S._Mooren_and_J._Kniep_2012_ Bullets_over_Gennep._Using_compositional_variation_ in_lead_musket_balls_in_battlefield_archaeology> (Consulta 15-II-2017).

KEEGAN, J. (1990): El rostro de la batalla, Madrid.

KRENN, P.; KALAUS, P.; HALL, B. (1995): Material culture and military history: testfiring early modern small arms, Material culture review / revue de la culture matérielle 42 (1), Nova Scotia, Canada, <https://journals.lib.unb.ca/index. $\mathrm{php} / \mathrm{MCR} /$ article/view/17669/22312> (Consulta 5-V-2017).

LICHNOWSKY, F. (1942): Recuerdos de la guerra carlista, 1837 -1839 , Madrid.

LOCKMAN, J. R. (2006): Elemental analysis of nineteenth century lead artifacts from Lewis and Clark and Hudson's Bay sites of the Pacific Northwest, Theses, Disertations, Profesional Papers. University of Montana, <http://scholarworks.umt. edu/etd $>$ (Consulta 2-I-2017).

MANDZY, A.; HALE, E.; MARIN, J. (2008): A Phase I Survey of the Blue Licks Battelfields, Kentucky Departament of Parks. Frankfort, Kentucky.

MILLER, D. (2010): Ballistics of 17th Century muskets, Cranfield University, <https://dspace.lib.cranfield.ac.uk/bitstream/ 1826/4605/3/David\%20Miller\%20PhD.pdf>.

ORTELLS, J.; NEBOT, S. (1839): Historia de la guerra civil de 1833 a 1839, Manuscrito inédito. Archivo del Reino de Valencia.

PASTOR MUÑOZ, F. J.; ADÁN POZA, M. J. (2001): El campo de batalla de Somosierra (30-XI-1808), Madrid.

PIRALA, A. (1868-1869): Historia de la guerra civil y de los partidos liberal y carlista. Segunda edición refundida y aumentada con la historia de la regencia de Espartero, Madrid.

RUBIO CAMPILLO, X. (2009): Modelització i simulació aplicades a la recerca i interpretació de camps de batalla, Tesis doctoral inédita. Universitat de Barcelona, <http://diposit. ub.edu/dspace/handle/2445/41457> (Consulta 1-VI-2013).

SANMARTíN, A. (1991): Vivencias de la I Guerra Carlista: las memorias de don Mariano Miquel y Polo (1834-1837), Boletín de la Sociedad Castellonense de Cultura LXVII, 131-177.

SCOTT, D.; BOHY, J.; BOOR, N.; HAECKER, C.; ROSE, W.; SEVERTS, P. (2016): Colonial Era Firearm Bullet Performance: an experimental Study for Archaeological Interpretation, $<$ https://bravodigs.org/wp-content/uploads/2019/04/Roundball-shooting-4-13-17-final.pdf> (Consulta 15-VI-2018). 
SELMA, S.; DUARTE, F.-X.; LOZANO, L. (2015): Obres de refortificació de les defenses del castell i la murada de la vila d'Orpesa durant les accions bèl-liques del S. XIX, La Linde 5, 109-138.

SIVILICH, D. M.; MILLER, H. M. (2016): Musket ball and small shot identification: A guide, University of Oklahoma Press.

SHURGER, A. (2015): The archaeology of the Battle of Lützen: an examination of 17th century military culture. $\mathrm{PhD}$ Tesis. University of Glasgow, <http://theses.gla.ac.uk/6508 /1/2015schuergerphd.pdf> (Consulta 18-VII-2018).

VIVAR, G.; RUT, M. (2015): El pecio Deltebre I. Un caso de arqueología subacuática, Desperta Ferro, arqueología e historia 3, 48-55.

VIVAR, G.; RUT, M.; TORRA, T. (2016): El Vaixell Deltebre I: resultats de les excavacions subaquàtiques en un vaixell de càrrega militar, 200 anys de la fi de la guerra del Francès a les Terres de l'Ebre. Actes del Congrés d'Historia i d'Arqueologia.Tortosa, 16, 17 i 18 de maig de 2014 (R.Salvadó, J. Martínez, eds.), Benicarló, 203-216.

VON RAHDEN, W.; RÚJULA, P.; HÜBNER, D. F. (2013): Cabrera: Recuerdos de la guerra civil española, Zaragoza.

VV. AA. (1837): Reglamento para el ejercicio y maniobra de la infantería, Madrid.

WILLEGAL, M. (1999): The accuracy of black powder muskets, $<$ https://www.fysh.org/ katie/wargames/documents/musket.pdf> (Consulta 12-I-2018).

WRZOSEK, J. (2012): Firearm bullets from Pultusk battelfield (1806). Recent Research into Medieval and Post Medieval Fireams and Artillery, Fasciuli Archaeologiae Historicae XXV, 87-96, <https://rcin.org.pl/Content/50095/WA308_ 68283_PIII368_Firearm-Bullets-from_I\%20.pdf> (Consulta 2-VI-2017). 